\title{
PYRITE: SHOCK COMPRESSION, ISENTROPIC RELEASE, AND COMPOSITION OF THE EARTH'S CORE
}

\section{Thomas J. Ahrens}

\author{
Seismological Laboratory, California Institute of Technology, Pasadena
}

\author{
Raymond Jeanloz
}

Department of Geology and Geophysics, University of California, Berkeley

\begin{abstract}
New shock wave data (to $180 \mathrm{GPa}$ ) for pyrite $\left(\mathrm{FeS}_{2}\right)$ shocked along (001) demonstrate that this mineral, in contrast to other sulfides and oxides, does not undergo a major pressure-induced phase change over the entire pressure range ( $320 \mathrm{GPa}$ ) now explored. (This is probably so because of the initial, low-spin 3-d, orbital configuration of $\mathrm{Fe}^{+2}$. The primary evidence which indicates that a large phase change does not occur is the approximate agreement of the shock velocity when extrapolated to zero particle velocity, $5.4 \mathrm{~km} / \mathrm{s}$, with the expected zero-pressure bulk sound speed of pyrite $(5.36$ to $5.43 \mathrm{~km} / \mathrm{s}$ on the basis of previous ultrasonic data). Pyrite displays a prominent elastic shock (or Hugoniot elastic limit) of $8 \pm 1$ GPa. The velocity of the elastic shock approaches $\mathbf{8 . 7 2}$ $\mathrm{km} / \mathrm{s}$ with decreasing shock pressure, the longitudinal elastic wave velocity. As shock pressure increases, the elastic shock velocity approaches $9.05 \mathrm{~km} / \mathrm{s}$ and the elastic shock becomes overdriven for shock pressures greater than about $120 \mathrm{GPa}$. Analysis of release isentrope data obtained via the pressure-particle velocity buffer method indicates that buffer particle velocities in all experiments are from $1.7 \%$ to $20 \%$ greater than expected for a Grüneisen ratio given by $1.56\left(\mathrm{~V} / \mathrm{V}_{0}\right)^{1.0}$. This discrepancy appears to result from volume increases upon pressure release of $0.04 \%$ to $4.5 \%$ which may result from shock-induced partial melting. The normalized pressure, finite-strain formalism for reducing Hugoniot data is extended to take into account initial porosity and shock-induced phase transitions. A least squares fit to the present and previous shock data for pyrite yields an isentropic bulk modulus, $K_{s}$, of $162 \pm 9$ $\mathrm{GPa}$ and $\mathrm{a}$ value of $\mathrm{dK}_{\mathrm{s}} / \mathrm{dP}=4.7 \pm 0.3$. This is close to the $145 \pm 3 \mathrm{GPa}$ bulk modulus observed ultrasonically. If the slight discrepancy in zero-pressure modulus is taken into account in the normalized pressure finite-strain formalism, a zero-pressure density of the shock-induced highpressure phase having a density some $2 \%$ to $3 \%$ less than pyrite is inferred to occur in the high-pressure shocked state. We suggest from this result, the release isentrope results, and limited phase diagram data that the Hugoniot states probably correspond to material which is partially to completely melted. Using the above derived equation of state and previous shock wave data for iron, both the seismologically determined density and bulk modulus distribution in the outer core are fit to models with various temperature distributions and varying weight percent sulfur. Good agreement between the shock wave derived equation of state and the density/bulk modulus relations of the liquid outer core are obtained for temperatures of $\sim 3000 \mathrm{~K}$ at the core/mantle boundary extending to 4400 $\mathrm{K}$ at the outer core-inner core boundary. For this thermal model a calculated sulfur content of $11 \pm 2 \%$ is obtained.
\end{abstract}

\section{Introduction and Background}

The outer, liquid core of the earth extends from a radius of 1217 to $3486 \mathrm{~km}$ and represents some $31 \%$ of the earth's mass. Birch [1952] pointed out that the liquid core is some $10 \%$ less dense than that of pure liquid iron under the appropriate pressure and temperature conditions.

\section{Copyright 1987 by the American Geophysical Union.}

Paper number 6B6220.

0148-0227/87/006B-6220\$05.00
Moreover, recent detailed analysis of shock wave and other thermodynamic data for iron by Jeanloz [1979] has demonstrated that the liquid core's bulk modulus is some $12 \%$ lower than that measured for pure iron. A number of authors have suggested that various possible cosmochemically abundant light elements are present in the earth's core. These include $\mathrm{Si}, \mathrm{C}$, and $\mathrm{S}$ le.g., Ringwood, 1966, 1979 ; Jacobs, 1975]. These elements are depleted by various factors in the accessible crust and mantle of the earth [Murthy, 1976; Ringwood, 1979; Ahrens, 1979; Anderson, 1982; Brown et al., 1984] relative to carbonaceous chondritic and solar abundances. Moreover recently, experimental evidence that oxygen could be present in the earth's core stems from the enhanced solubility of $O$ in liquid iron observed at high temperatures and pressures [Ohtani and Ringwood, 1984; Ohtani et al., 1984]. Also Fukai and Akimoto [1983] suggested that enhanced solubility of hydrogen may occur at high pressures in iron and that this element should also be considered as possibly alloying with iron in the outer core. Although it is possible that the light material in the core is actually a mixture of several elements rather than one element, as pointed out by both Ringwood [1979] and Stevenson [1981], on geochemical and dynamical grounds, respectively, it is important to recognize that exactly what the light element content of the core is, constrains the chemical environment which existed during the accretion of the earth with its present volatile budget. Volatiles affected by core formation include water [Lange and Ahrens, 1984; Hariya, 1984] and noble gases [e.g., Donahue and Pollack, 1983; Lewis and Prinn, 1984] as well as other species such as $\mathrm{CH}_{4}$ and $\mathrm{CO}_{2}$, important to man and the environment [Lange and Ahrens, 1986; Gold and Soter, 1980].

What different compositional models of the earth's core tell us about the accretion process and the total volatile budget has been studied to various degrees in the case of $\mathrm{Si}, \mathrm{O}, \mathrm{H}$, and S. Briefly, Ringwood [1979] points out that if the earth accreted homogeneously, when it reached a radius in excess of $5000 \mathrm{~km}$, selective volatilization of $\mathrm{SiO}$ would occur at surface temperatures above $1800 \mathrm{~K}$, and some of the enstatite-rich chondritic material would react to form forsterite. Upon reduction of some of the $\mathrm{SiO}$ in the silicate to metallic silicon, this material could have been incorporated in to a silicon-alloy iron core.

Ohtani et al. [1984] have shown that $\mathrm{FeO}$ will dissolve in liquid iron above $\sim 2500-2900 \mathrm{~K}$ at atmospheric pressures, but such solution occurs at temperatures as low as $2500 \mathrm{~K}$ at $30 \mathrm{GPa}$. In contrast, incorporation of $\mathrm{H}$ into the core would appear to require very reducing surface conditions and inhibition of the iron-water surface reaction [Ringwood, 1979; Lange and Ahrens, 1984].

It $h$ as been argued that $S$ cannot be the only light element in the core because then the earth would appear to be enriched and not depleted in $S$ relative to similarly volatile elements in the earth's crust and upper mantle Brown et al., 1984]. Because of the low eutectic temperature (1260 $\mathrm{K}$ ) in the $\mathrm{Fe}-\mathrm{S}$ system and the low shock pressure required to impact melt FeS $(\sim 33 \mathrm{GPa})$ [Anderson and Ahrens, 1986 , an iron sulfide core would have started to form as the earth accreted and reached approximately 0.5 of its present radius. We note that the assumption that sulfur is the major light element alloying with iron in the core is supported by the recent work of Jones and Drake [1982] and Brett [1984], who find that the present siderophile minor element distribution of the earth's mantle is con- 
TABLE 1. Hugoniot and Release

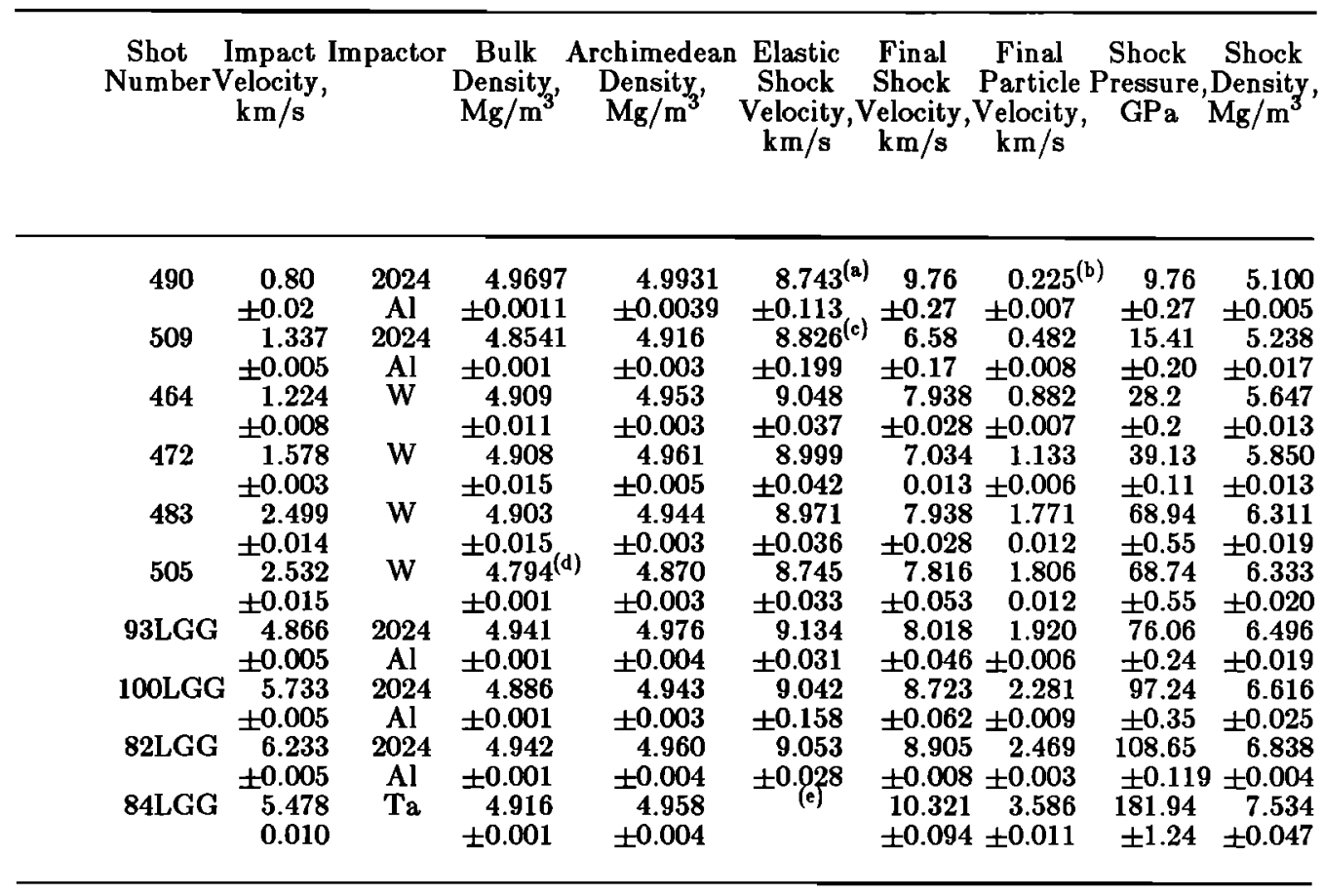

(a) Free surface velocity, elastic shock $=0.33 \pm 0.17 \mathrm{~km} / \mathrm{s}$. Elastic shock amplitude (HEL) $=7.27 \pm 1.52 \mathrm{GPa}$.

(b) Only elastic shock observed, final calculated state uses this velocity for impedance match solution.

(c) Free-surface velocity, elastic shock $=0.40 \pm 0.013 \mathrm{~km} / \mathrm{s}$. HEL $=8.56 \pm 0.19 \mathrm{GPa}$.

(d) Archimedean density used instead of bulk density for determination of shock state.

(e) Elastic shock overdriven.

sistent with that required for equilibrium with iron core material being formed at near-surface, but reducing, conditions in an accreting earth [e.g., Stevenson, 1981].

It has been argued for example in Ringwood [1979] (and discussed by Brown et al. [1984]) that if $S$ were the major light element in the core, the upper mantle abundances of other nonsiderophile elements with similar or greater volatility than $\mathrm{S}$ are so low that the earth would, relative to these other elements (e.g., $\mathrm{Sn}, \mathrm{Zn}, \mathrm{Se}, \mathrm{Te}, \mathrm{Ge}, \mathrm{F}, \mathrm{Ag}, \mathrm{K}$, and $\mathrm{Na}$ ), be enriched in $\mathrm{S}$ on account of $10 \%$ or $11 \%$ of the outer core being sulfur. This argument is sound. However, the mantle as a whole may be not as depleted in these volatile elements as our limited upper mantle sampling suggests. It should be pointed out that many of these elements concentrate in a component of the mantle which may have been produced when the protomantle was partially melted. The recent work of Rigden et al. [1984] prescribing the density of such basalticlike silicate compositions relative to mean upper mantle densities suggests that for partial melting in the mantle at pressures higher than 6 to $8 \mathrm{GPa}$, the resulting liquids will sink, not rise. Hence the mantle of the earth as a whole may have a larger inventory of some of the large ion lithophile elements and other volatile elements than an upper mantle sample which could be depleted in these elements may suggest. Both the possible existence of large ion lithophile elements and volatile enrichments in the lower mantle and the fact that partial melting upon impact accretion of FeS-rich compositions occurs early during earth accretion and core growth, make sulfur a likely element alloying with iron in the liquid outer core of the earth.

Previously [Ahrens, 1979; Brown et al., 1984] have studied dynamic compression of $\mathrm{Fe}_{\mathrm{S}} \mathrm{S}$ (pyrrhotite). Because pyrrhotite has a relatively low (0.39) mass fraction of sulfur relative to other minerals, it appears to be a good choice for studying the effect of a small amount of sulfur on the behavior of iron and is useful to place constraints on the sulfur content of the liquid outer core of the earth. In contrast, pyrite has a higher mass fraction of sulfur (0.53). However, as shown in the present study, and not appreciated previously, by Ahrens [1979] or in an earlier analysis by Batalov et al. [1976], this mineral does not undergo a major shock-induced phase change and thus removes a complication which unfortunately is imposed on the data analysis both in the case of iron and pyrrhotite. Although it is clear from the study of Brown and McQueen [1982] that the Hugoniot of iron represents the properties of the liquid above shock pressures of $250 \mathrm{GPa}$, the range in which either the Hugoniot of pyrite or pyrrhotite represents the liquid is uncertain. However, it should be pointed out because sulfur is simply a less important constituent in the core, the question of a liquid or solid Hugoniot is less critical in the case of the sulfide minerals.

Previously, Simakov et al. [1974] reported six Hugoniot data in the range from 28.9 to $320 \mathrm{GPa}$, which were independently analyzed in terms of hypothetical phase transitions by Batalov et al. [1976] and Ahrens [1979]. Previously, ultrasonic elastic constant data for pyrite are reported by several authors and collected by Simmons and Wang [1971]. In the present work some 10 new Hugoniot and release data extending to $180 \mathrm{GPa}$ are presented, and a complete equation of state is derived. Both the Hugoniot elastic limit and the range of shock pressures in which a double shock wave exists are defined. We present new methods for reducing buffer-method release isentrope data to define release paths in the pressure-density plane and apply the reduced pressure/finite-strain formalism of Birch [1978] as specialized to shock data by Heinz and Jeanloz 1984 to infer (probably) partial melting in the shock state. Finally, the new data for pyrite are combined with existing shock wave data for iron and fit to the seismologically derived pressure/density/bulk moduli relations for the 
Isentrope Data for Pyrite

\begin{tabular}{|c|c|c|c|c|c|c|c|}
\hline $\begin{array}{c}\text { Final } \\
\text { State } \\
\text { Free- } \\
\text { Surface } \\
\text { Velocity, } \\
\mathrm{km} / \mathrm{s}\end{array}$ & $\begin{array}{c}\text { Buffer } \\
\text { Material }\end{array}$ & $\begin{array}{c}\text { Buffer } \\
\text { Shock } \\
\text { Velocity, } \\
\text { km/s }\end{array}$ & $\begin{array}{c}\text { Release } \\
\text { State } \\
\text { Pressure, } \\
\text { GPa }\end{array}$ & $\begin{array}{c}\text { Release } \\
\text { State } \\
\text { Particle } \\
\text { Velocity, } \\
\text { km/s }\end{array}$ & $\begin{array}{c}\text { Calculated } \\
\text { Release } \\
\text { State } \\
\text { Particle } \\
\text { Velocity, } \\
\text { km/s }\end{array}$ & $\begin{array}{l}\text { Calculated } \\
\text { Release } \\
\text { State } \\
\text { Density, } \\
\mathrm{Mg} / \mathrm{m}^{3}\end{array}$ & $\begin{array}{c}\text { Calculated } \\
\text { Excess Isentropic } \\
\text { Release Volume, } \\
\%\end{array}$ \\
\hline $\begin{array}{c}\text { (b) } \\
\\
0.787 \\
\pm 0.023 \\
1.749 \\
\pm 0.082 \\
2.47 \\
\pm 0.22 \\
3.834 \\
\pm 0.212\end{array}$ & $\begin{array}{l}\text { Lexan } \\
\text { Lexan } \\
\text { Lexan } \\
\text { Lexan } \\
\text { Lexan } \\
\text { Lexan } \\
\text { Fused } \\
\text { Quartz } \\
\text { Fused } \\
\text { Quartz } \\
\text { Fused } \\
\text { Quartz } \\
\text { Fused } \\
\text { Quartz }\end{array}$ & $\begin{array}{r}2.69 \\
\pm 0.01 \\
2.78 \\
\pm 0.01 \\
4.965 \\
\pm 0.025 \\
5.407 \\
\pm 0.106 \\
6.894 \\
\pm 0.045 \\
6.831 \\
\pm 0.180 \\
5.766 \\
\pm 0.023 \\
6.436 \\
\pm 0.014 \\
6.746 \\
\pm 0.030 \\
9.220 \\
\pm 0.045\end{array}$ & $\begin{array}{r}0.61 \\
\pm 0.03 \\
1.42 \\
\pm 0.03 \\
9.87 \\
\pm 0.15 \\
12.61 \\
\pm 0.69 \\
24.41 \\
\pm 0.41 \\
23.8 \\
\pm 1.6 \\
37.3 \\
\pm 0.3 \\
47.6 \\
\pm 0.2 \\
52.84 \\
\pm 0.52 \\
103.89 \\
\pm 1.08\end{array}$ & $\begin{array}{r}0.191 \\
\pm 0.008 \\
0.427 \\
\pm 0.008 \\
1.667 \\
\pm 0.016 \\
1.955 \\
\pm 0.069 \\
2.968 \\
\pm 0.030 \\
2.926 \\
\pm 0.120 \\
2.936 \\
\pm 0.014 \\
3.358 \\
\pm 0.009 \\
3.554 \\
\pm 0.019 \\
5.113 \\
\pm 0.028\end{array}$ & $\begin{array}{r}1.373 \\
1.825 \\
2.760 \\
2.769 \\
2.705 \\
3.226 \\
3.495 \\
4.665\end{array}$ & $\begin{array}{l}5.234 \\
5.297 \\
5.543 \\
5.530 \\
5.802 \\
5.960 \\
6.031 \\
6.642\end{array}$ & $\begin{array}{l}4.5 \\
0.65 \\
0.92 \\
0.53 \\
0.94 \\
0.24 \\
0.004 \\
1.4\end{array}$ \\
\hline
\end{tabular}

earth. This results in constraints on the weight percent sulfur and to a lesser degree the temperature gradient, for a model liquid core assumed to be only a molten iron-sulfur liquid.

\section{Experimental}

Ten samples of natural pyrite from Ambasuguas, Spain were machined in to specimens 3 to $4 \mathrm{~mm}$ thick, flat and parallel to within $\pm 0.005 \mathrm{~mm}$ with lateral dimensions of 12 to $14 \mathrm{~mm}$. Although the crystals were not specifically oriented, their well-defined crystal faces resulted in our propagating shocks within $\pm 2^{\circ}$ of the (001) direction.

Four microprobe analyses (A. Chodos, analyst) and reflection microscopy indicated only one phase was present in the samples. Three of the samples analyzed yielded data indicating a marginally detectable quantity of $\mathrm{Ni}$, varying from 0.03 to 0.08 wt. \% which was accounted for by assuming a pyrite-millerite (NiS) solid solution. Other elements for which we sought but did not find detectable concentrations $(\sim 0.1$ wt. $\%)$ using $\mathrm{X}$-ray dispersive analysis included $\mathrm{Mg}, \mathrm{Si}, \mathrm{Ti}$, and $\mathrm{Co}$. After taking in to account the $\mathrm{Ni}$ content, the present samples appear to be still slightly more iron rich than $\mathrm{FeS}_{2}$. Averaging the four analyses yielded the following solid solution representation of the sample material:

$$
\begin{gathered}
0.0715 \mathrm{FeS} \text { (troilite) }+0.0008 \mathrm{NiS} \text { (millerite) } \\
+\mathrm{FeS}_{2} \text { (pyrite) }
\end{gathered}
$$

The theoretical ideal solution density for this composition is $5.0002 \mathrm{Mg} / \mathrm{m}^{3}$. This compares with $5.011 \mathrm{Mg} / \mathrm{m}^{3}$ for pure pyrite. The theoretical value is close to the average of the Archimedean densities (Table 1) that were determined by measuring the mass of samples in air and toluene at carefully controlled temperatures. The average density is
$4.947 \pm 0.034 \mathrm{Mg} / \mathrm{m}^{3}$. This Archimedean density value implies that our samples had an average inaccessible porosity of $1.08 \%$. The average of nine bulk sample densities was $4.914 \mathrm{Mg} / \mathrm{m}^{3}$, or $1.94 \%$ porosity. The latter value is close to the single value of bulk density, $4.91 \mathrm{Mg} / \mathrm{m}^{3}$, reported by Simakov et al. [1974].

The samples after machining were mounted on $2024 \mathrm{Al}$, $W$, and Ta driver plates (Table 2). Metal Hyer plate bearing projectiles were launched using the Caltech $40-\mathrm{mm}$ propellant and 25-mm light gas guns [Ahrens, 1987]. The projectiles impacted the sample assemblies at speeds varying from 0.8 to $5.5 \mathrm{~km} / \mathrm{s}$ (Table 1). Projectile velocity was determined by measuring laser interruption intervals [Ahrens et al., 1971] and via double exposure X-ray photography [Rigden et al., 1984] on the $40-\mathrm{mm}$ apparatus and via X-ray shadowgraph on the light gas gun Jeanloz and Ahrens, 1977]. All three systems employ time interval counter systems. Streak camera photography determined the elastic and deformational shock velocity and the freesurface velocity associated with the elastic and deformational shocks on the $40-\mathrm{mm}$ and light gas gun apparatus [Vassiliou and Ahrens, 1982]. Isentropic release wave states were obtained upon reflection of the shock against 2-mmthick lexan and fused quartz buffer samples on the $40-\mathrm{mm}$ and light gas guns, respectively. The shock velocity is measured in the buffer material. From the known buffer equation of state, the pressure and particle velocity of the isentropically partially released state are determined [Ahrens and Rosenberg, 1968].

\section{Results}

Except for the highest pressure experiment (84LGG), double-shock structure was observed in all experiments. Although the initial shock velocity demonstrates some scatter, which can in part, be correlated with variations in 
TABLE 2. Equation of State Standards

\begin{tabular}{|c|c|c|c|c|}
\hline Material & $\begin{array}{c}\rho_{0} \\
\mathrm{Mg} / \mathrm{m}^{3}\end{array}$ & $\begin{array}{c}\mathrm{C}_{\mathrm{o}} \\
\mathrm{km} / \mathrm{s}\end{array}$ & $\mathbf{S}$ & Reference \\
\hline$\overline{2024 \mathrm{Al}}$ & 2.785 & 5.328 & 1.338 & McQueen et al. [1970] \\
\hline W & 19.224 & 4.029 & 1.237 & McQueen et al. 1970 \\
\hline $\mathrm{Ta}$ & 16.678 & 3.293 & 1.307 & Mitchell and Nellis [1981] \\
\hline Lexan $(<2.0 \mathrm{~km} / \mathrm{s}) *$ & 1.193 & 2.399 & 1.539 & Marsh [1980] \\
\hline$(2.0-3.0 \mathrm{~km} / \mathrm{s})^{*}$ & 1.193 & 2.449 & 1.498 & Marsh [1980] \\
\hline Fused quartz & 2.204 & 1.0861 & 1.599 & Jackson and Ahrens [1979] \\
\hline
\end{tabular}

*Particle velocity.

initial bulk velocity, the initial shock velocity data when plotted versus final shock pressure demonstrate a consistent increase in velocity with final driving pressure. Because the velocity appears to extrapolate to approximately the value of the longitudinal elastic velocity along (001), $8.72 \mathrm{~km} / \mathrm{s}$ (Figure 1) and the absence of indications from the Hugoniot release isentropes which suggest phase changes, we infer that this initial shock is an elastic shock. The apparent variation in shock velocity is presumably the result of the phenomenon of the elastic shock precursor decay (stress relaxation) described in iron and other metals, and semiconducting elements, oxides, and here for the first time, a sulfide Ahrens and Duvall, 1966; Ahrens, 1966; Asay et al., 1972; McQueen et al., 1970; Grady, 1977]. Two shots (490 and 509) yielded inclined mirror freesurface velocity records which gave values of $8 \pm 1 \mathrm{GPa}$ for the Hugoniot elastic limit. The curve drawn through the elastic velocity data (Figure 1) and the shock velocity/particle velocity relation (Figure 2) indicates that the elastic shock will be overdriven at about $120 \mathrm{GPa}$. This is consistent with its absence only in shot 84LGG.

The shock velocity/particle velocity $\left(U_{s}-u_{p}\right)$ relation is well satisfied by a straight line fit which extrapolates closely to the average value of the ultrasonically determined bulk sound speed, Co $=\left(\mathrm{K}_{0 \mathrm{~s}} / \rho_{0}\right)^{1 / 2}$. Simmons and Wang [1971] list values which vary from 5.36 to $5.43 \mathrm{~km} / \mathrm{s}$. Here $K_{0 s}$ is the isentropic bulk modulus and $\rho_{0}$ is the single-crystal density. The $r^{2}$ value for the fit given in Figure 2 which omits the lower pressure datum of the present and Simakov et al. [1974] data set (13 points) is 0.997 , whereas the slightly different fit used in the subsequent analysis included shot 509 gave an $\mathrm{r}^{2}=0.994$ and parameters are given in Table 3 (14 points). Because of the good correlation of Co determined from Figure 2 and the ultrasonic value of $\mathrm{Co}$, we infer no major phase change occurs in $\mathrm{FeS}_{2}$ over the pressure range (to $320 \mathrm{GPa}$ ), which has been

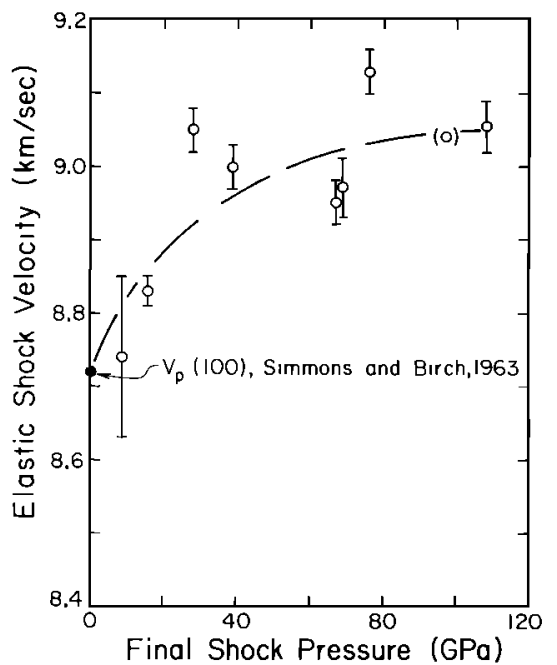

Fig. 1. Elastic shock velocity versus final shock pressure for pyrite, shocked along (001). studied to date. This conclusion differs from those inferred by early analyses by Batalov et al. [1976] and Ahrens [1979], who considered only the earlier, sparser data set of Simakov et al. [1974]. Recently Jephcoat et al. [1983] also found no transition in pyrite to $40 \mathrm{GPa}$ upon hydrostatic compression. Jackson and Ringwood [1981] correctly inferred only on the basis of ultrasonic and the Simakov et al. data that no phase change occurred in pyrite.

Since the above analysis of the $U_{\mathrm{s}}-\mathrm{u}_{\mathrm{p}}$ relation indicates no major phase changes upon shock compression, it is possible to use the STP value of the Grüneisen parameter, $\gamma_{0}$, to construct a complete equation of state. As indicated in Table $3, \gamma_{0}$ is calculated using a value of $\alpha$, the thermal expansion coefficient of $13.7 \times 10^{-5} \mathrm{~K}^{-1}$ [Skinner, 1966], $\mathrm{K}_{0 \mathrm{~s}}$ of 147.9 GPa [Simmons and Birch, 1963], $\rho_{o}$ and $C_{p}$ of $5.016 \mathrm{Mg} / \mathrm{m}^{3}$ and $0.518 \mathrm{~kJ} / \mathrm{kg} / \mathrm{K}$ [Robie et al., 1978]. These yield a value of 1.56 from the formula

$$
\gamma_{\mathrm{o}}=\alpha \mathrm{K}_{0 \mathrm{~s}} / \mathrm{C}_{\mathrm{p}} \rho_{\mathrm{o}}
$$

The particle velocity $u_{s}$ achieved upon isentropic unloading from pressure, $P_{H}$, and particle velocity, $u_{H}$, to $P_{s}$ should for a known Gruneisen parameter, be exactly calculable from (Figures 3a and $3 b$ )

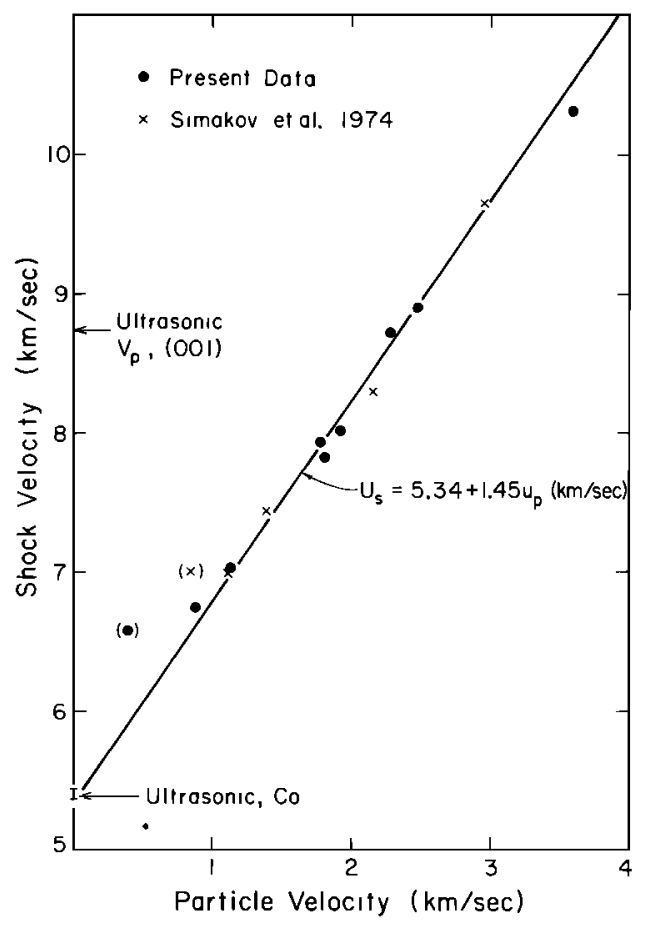

Fig. 2. Shock velocity versus particle velocity for pyrite. Data in parentheses not included in indicated fit (as elastic-deformational shock interaction may not have been properly taken into account). 

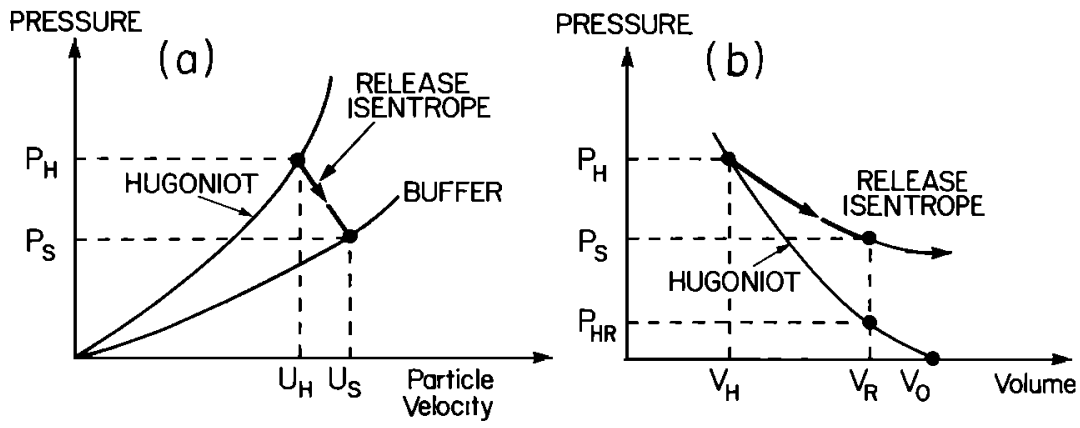

Fig. 3. Release isentrope (a) pressure-particle velocity and (b) pressure-volume relations. Equations (3) and (4) describe state along release isentrope indicated by heavy lines.

$$
\begin{gathered}
E_{H^{-}} \int_{V_{H}}^{V_{R}} P_{s} d V=E_{H R}+\left(P_{s}-P_{H R}\right) V / \gamma \\
u_{s}=u_{H}+\left(\int_{V_{H}}^{v_{R}} P_{s} d V\right)^{1 / 2}
\end{gathered}
$$

where $\gamma / V$ is assumed constant, and $E_{H}$ and $E_{H R}$ are the Hugoniot energy at states $\left(P_{H}, V_{H}\right)$, and $\left(P_{H R}, V_{R}\right)$, given by

$$
\begin{aligned}
\mathrm{E}_{\mathrm{H}} & =\mathrm{P}_{\mathrm{H}}\left(\mathrm{V}_{\mathrm{o}}-\mathrm{V}_{\mathrm{H}}\right) / 2 \\
\mathrm{E}_{\mathrm{HR}} & =\mathrm{P}_{\mathrm{HR}}\left(\mathrm{V}_{\mathrm{o}}-\mathrm{V}_{\mathrm{R}}\right) / 2
\end{aligned}
$$

Also $P_{8}$ is the release pressure obtained at the buffersample interface upon reflection of a shock of amplitude $P_{H}$ with particle velocity $u_{H}$. Equations (3)-(6) have been solved numerically to yield the release isentropes in both the pressure/particle velocity plane and pressure-volume plane along paths indicated by the heavy lines in Figures $3 \mathrm{a}$ and $3 \mathrm{~b}$. The pressure-density path for two of nine release isentropes is calculated using (3) and plotted in Figure 4 . We note in Table 1 that in all cases the value of $u_{s}$, calculated using (3), with the assumption that $\gamma_{0}=1.56$ and $\gamma / \mathrm{V}$ is a constant is always (for all eight experiments where buffer data are available) slightly greater (by $1.7 \%$ to $21 \%$ ) than those, $u_{r}$ measured. Several explanations of this discrepancy are possible. Two which have been considered are that the calculated value of $\gamma_{0}$ (from (2)) used is too low. We find that values of $\gamma_{0} \sim 4$ are required to fit the theoretical values of $u_{s}$ to $u_{r}$. Since the values of $\gamma$ for minerals, compounds, and elements generally only range over the values of $\sim 1$ to 2.5 , we exclude this possibility. A more likely explanation is that partial or complete melting is occurring upon isentropic pressure release. The increase in volume, $\Delta \mathrm{Vm}$, can be approximately calculated from the discrepancy between $u_{s}$ and $u_{r}$ using the equation [Lyzenga and Ahrens, 1978]

$$
\Delta \mathrm{Vm} \cong 4\left(\mathrm{u}_{\mathrm{r}}-\mathrm{u}_{\mathrm{s}}\right)^{2} /\left(\mathrm{P}_{\mathrm{H}}+\mathrm{P}_{\mathrm{s}}\right)
$$

which yields approximate volume increases of $0.04 \%$ to $4.5 \%$ (Table 1 ) averaging $1.1 \%$ in eight experiments.

The Hugoniot pressure in terms of a Mie-Grüneisen equation of state is [e.g., Ahrens, 1979]

$$
\begin{aligned}
P_{H}= & \left\{P_{S}+(\gamma / V)\left[\left[\int_{V_{02}}^{V} P_{S} d V\right)-E_{t r}\right]\right\} \\
& x\left\{1-(\gamma / V)\left(V_{o o}-V\right) / 2\right\}^{-1}
\end{aligned}
$$

Here, sample porosity and phase transformations are accommodated: $V_{00}$ is the initial sample volume (whether or not porous) and $E_{\mathrm{tr}}$ is the internal energy of transformation, with $\mathrm{P}_{\mathrm{s}}$ and $\gamma$ being the isentrope pressure and Grüneisen parameter at the Hugoniot volume. If the Hugoniot represents a high-pressure phase, $V_{02}$ is its zeropressure volume. Without a phase transformation, $\mathrm{E}_{\mathrm{tr}}=$ 0 , and $V_{02}$ is the crystal volume of the starting material; if in addition there is no porosity, $\mathrm{V}_{00}=\mathrm{V}_{02}$.

As first pointed out by Jeanloz and Ahrens [1980], (8) can be expressed as a linear least squares problem in which the $\mathbf{P}_{\mathbf{H}}(\mathrm{V})$ Hugoniot data are fitted to an Eulerian finitestrain form of the isentrope $P_{s}(V)$. The justification for using the Eulerian finite-strain (Birch-Murnaghan) type of equation of state is that it is empirically known to be exceptionally successful in relating compression data to independently measured elastic moduli [e.g., Birch, 1978; Heinz and Jeanloz, 1984].

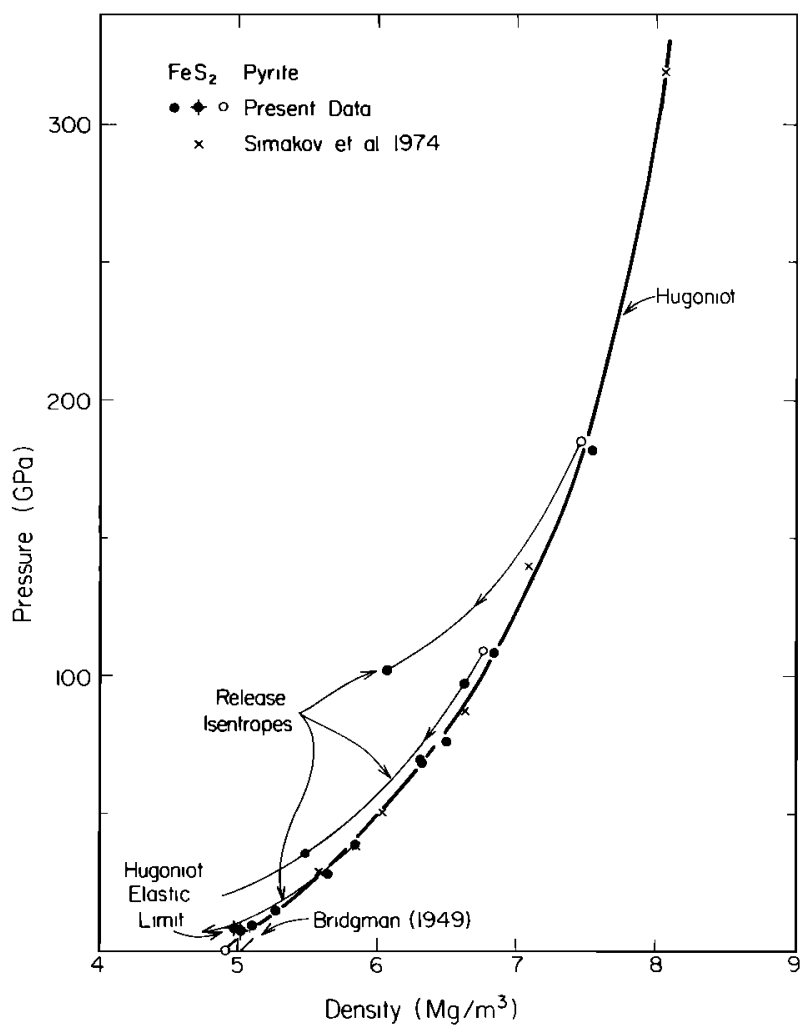

Fig. 4. Shock pressure versus density for pyrite. An analytic fit was used for calculating pressure-density isentropes; states (indicated by open circles) upon which isentropes are centered do not exactly coincide with Hugoniot data. 
TABLE 3. Equations of

\begin{tabular}{|c|c|c|c|c|c|c|}
\hline Material & $\begin{array}{c}\text { Crystal } \\
\text { Density, } \\
\mathrm{Mg} / \mathrm{m}^{3}\end{array}$ & $\begin{array}{c}\text { Bulk } \\
\text { Density, } \\
\mathrm{Mg} / \mathrm{m}^{3}\end{array}$ & $\begin{array}{c}\mathrm{C}_{\mathrm{or}} \\
\mathrm{km} / \mathrm{s}\end{array}$ & $S$ & $\begin{array}{c}\mathrm{S}^{\prime \prime} \\
(\mathrm{km} / \mathrm{s})^{-1}\end{array}$ & $\begin{array}{l}\mathrm{K}_{\mathrm{os}} \\
\mathrm{GPa}\end{array}$ \\
\hline Pyrite & $4.947^{(\mathrm{a})}$ & $4.914^{(b)}$ & $5.478^{(c)}$ & $1.401^{(\mathrm{c})}$ & \multirow{3}{*}{-0.068} & \multirow{3}{*}{$\begin{array}{c}162^{(\mathrm{d})} \\
\pm 1.1 \\
0.068^{(\mathrm{h})} \\
\pm 0.7 \\
140.0^{(\mathrm{l})} \\
\pm 3.2\end{array}$} \\
\hline Iron & $8.31^{(\mathrm{g})}$ & $7.85^{(\mathrm{b})}$ & $3.574^{(h)}$ & $1.92^{(\mathrm{h})}$ & & \\
\hline Iron & $8.31^{(\mathrm{g})}$ & $7.85^{(\mathrm{k})}$ & $3.80^{(\mathrm{k})}$ & $1.58^{(k)}$ & & \\
\hline
\end{tabular}

(a) Measured average Archimedean density.

(b) Measured average bulk density.

(c) Fit to 14 data points (present data, plus Simikov et al. [1974]).

(d) Least squares fit to all but the three lowest data points taking in to account individual initial bulk densities.

(e) First value least squares fit of (9) to average value of $C$ for release isentropes, $n=-0.6$; second value, $\mathrm{n}=1.0$.

(f) First term 3R, second term after Brown et al. [1984].

(g) Jeanloz $[1979]$

h) McQueen et al. [1970].

(i) Fit similar to that of (d), except for Hugoniot data between 40.9 and $319 \mathrm{GPa}$.

(j) Transition energy of melting [Brown et al., 1984].

(k) Al'tshuler et al. [1962].

(l) Fit similar to that of (k), except for Hugoniot data range from 35 to $315 \mathrm{GPa}$.

Thus the isentrope derived from the Hugoniot is expressed as a normalized pressure ( $F_{\mathrm{HS}}$ ) that is a polynomial expansion in terms dependent on the Eulerian strain:

$$
\mathrm{f}=\left[\left(\mathrm{V}_{\mathrm{o}} / \mathrm{V}\right)^{2 / 3}-1\right] / 2
$$

Specifically [see Heinz and Jeanloz, 1984],

$$
\mathrm{F}_{\mathrm{HS}}^{\prime}=\mathrm{F}_{\mathrm{HS}}+\Delta \mathrm{F}_{\mathrm{tr}}=\mathrm{K}_{0 \mathrm{~S}}\left(1-2 \xi_{\mathrm{S}} \mathrm{f}_{3 \mathrm{H}}+4 \xi_{\mathrm{s}} \mathrm{f}_{4 \mathrm{H}}^{2}+\ldots\right)(10)
$$
with

$$
\begin{gathered}
F_{H S}=P_{H}\left[1-\gamma\left(R(2 f+1)^{1.5}-1\right) / 2\right] /\{[1+(2-1.5 \gamma) r] \\
\left.(3 f)(1+2 f)^{1.5}\right\}
\end{gathered}
$$

where $\mathrm{R} \equiv \mathrm{V}_{\mathrm{oo}} / \mathrm{V}_{\mathrm{o}}$

$$
\begin{gathered}
\Delta \mathrm{F}_{\mathrm{tr}}=\left(\mathrm{E}_{\mathrm{tr}} / \mathrm{V}_{\mathrm{o}}\right) \gamma\{3 \mathrm{f}[1+(2-1.5 \gamma) \mathrm{f}]\}^{-\mathrm{I}} \\
\mathrm{f}_{3 \mathrm{H}}=\mathrm{f}[1+(2-\gamma) \mathrm{f}] /[1+(2-1.5 \gamma) \mathrm{f}] \\
\mathrm{f}_{4 \mathrm{H}}=\mathrm{f}\{[1+(2-0.75 \gamma) \mathrm{r}] /[1+(2-1.5 \gamma) \mathrm{f}]\}^{0.5}
\end{gathered}
$$

Terms (11) - (14) are considered measured (or independently known), and these are used to determine the equation-of-state parameters for the phase represented by the Hugoniot: $K_{0 S}$ is the zero-pressure isentropic bulk modulus and

$$
\begin{gathered}
\xi=3\left(4-\mathrm{K}_{0}^{\prime}\right) / 4 \\
\varsigma=(3 / 8)\left[\mathrm{K}_{0} \mathrm{~K}_{0}^{\prime \prime}+\mathrm{K}_{0}^{\prime}\left(\mathrm{K}_{0}^{\prime}-7\right)+143 / 9\right]
\end{gathered}
$$

are the third- and fourth-order terms in the finite-strain expansion [Birch, 1978]. Here $K_{0}^{\prime}$ is $\left(\partial K_{0 S} / \partial P\right)_{8}$. Throughout these equations, subscripts zero and $\mathrm{S}$ indicate zero-pressure and isentropic conditions, respectively, and prime indicates differentiation with respect to pressure.

Equation (10) is analogous to Birch's F - r expression for compression data, but now modified to include the thermal correction to Hugoniot data. The normalized isentropic pressure, in contrast to (10) is

$$
F=P_{\mathrm{s}}\left[3 f(1+2 f)^{5 / 2}\right]^{-1}
$$

which reflects the derivative of the equation of state, converging to $K_{0 S}$ as pressure goes to zero $(f=0)$. The energy of transition is included in (10) and (12) as a perturbation term $\Delta F_{t r}$, which is typically much smaller than $F_{H S}$. Except for the incorporation of porosity and phase transition effects, the present analysis is similar to the development in the work by Heinz and Jeanloz [1984]. The appendix gives expressions for the propagation of errors.

The present results and those of Simakov et al. [1974] for pyrite are shown as raw Hugoniot data ( $F$, f: using Hugoniot density and pressure in (9) and (17): no symbols) and reduced points ( $\mathrm{F}_{\mathrm{HS}}, \mathrm{f}_{3 \mathrm{H}}$ : open and solid symbols) in Figure 5. For the present purposes the approximation $\mathrm{f}_{4 \mathrm{H}} \stackrel{\sim}{=} \mathrm{f}_{3 \mathrm{H}}$ is adequate, so the reduced values of normalized pressure $\mathrm{F}_{\mathrm{HS}}$ are expected to follow a polynomial curve in the strain $\mathrm{f}_{3 \mathrm{H}}$. To calculate the strain, the crystal density $\rho_{0}=1 / \mathrm{V}_{0}=5.002 \mathrm{Mg} / \mathrm{m}^{3}$ is used and the Grüneisen parameter is assumed to be given by Bassett et al. [1968].

$$
\gamma=\gamma_{0}\left(\mathrm{~V} / \mathrm{V}_{0}\right)^{\mathrm{q}}
$$

with uncertainties of $\gamma_{0}=1.56( \pm 0.16)$ and $q=1.0( \pm 0.5)$. For each datum, the measured bulk density $\rho_{00}$ (Table 1 ) is used to define the porous volume, and it is assumed that no phase transition occurs $\left(\Delta \mathrm{F}_{\mathrm{rr}}=0 ; \mathrm{K}_{0 \mathrm{~S}}, \xi_{\mathrm{S}}\right.$, $\varsigma_{\mathrm{s}}$, and $\gamma$ all pertain to the initial pyrite structure).

The present data and those of Simakov et al. are remarkably compatible, recognizing that an $\mathrm{F}$ - $f$ plot such as Figure 5 tends to exaggerate scatter or discrepancies among compression measurements [Birch, 1978]. Although the present lowest pressure points fall well above the trend of the data in the figure, these deviations can be ascribed to the small $(\sim 1-2 \%)$ initial porosities of the samples. That is, the porosity may not be fully overcome in the lowest pressure measurements. Similarly, the highest point of Simakov et al. exhibits a large value of $F_{H S}$. However, this cannot be plausibly explained by initial porosity. Instead, a slope or curvature in the $\mathrm{F}_{\mathrm{HS}}-f_{\mathrm{H}}$ trend (i.e., third- or higher-order terms in the equation of state), the effect of a phase transition (including melting), or large uncertainties in that measurement can all be offered as explanations for this last datum. Indeed, pyrite is likely to be molten along the Hugoniot at the pressures of the highest two or three points in Figure 3. 
State, Pyrite and Iron

\begin{tabular}{lllll}
\hline $\mathrm{dK}_{\mathrm{os}} / \mathrm{dP}$ & $\gamma_{\mathrm{o}}$ & $\mathrm{n}$ & $\begin{array}{c}\mathrm{E}_{\mathrm{TR}} \\
\mathrm{MJ} / \mathrm{Mg}\end{array}$ & $\begin{array}{c}\mathrm{C}_{\mathrm{V}}, \\
\mathrm{kJ} / \mathrm{kg} / \mathrm{K}\end{array}$ \\
\hline $\begin{array}{c}4.7^{(\mathrm{d})} \\
\pm 0.3\end{array}$ & $1.56^{(\mathrm{e})}$ & 1.0 & & $0.624+0.080 \times 10^{-3}\left(\mathrm{~V} / \mathrm{V}_{\mathrm{o}}\right) \mathrm{T}^{(\mathrm{f})}$ \\
$\mathbf{5 . 2 8 ^ { ( \mathrm { i } ) }}$ & $2.2^{(\mathrm{g})}$ & $1.62^{(\mathrm{g})}$ & $0.9^{(\mathrm{j})}$ & $0.447+0.08 \times 10^{-3}\left(\mathrm{~V} / \mathrm{V}_{\mathrm{o}}\right) \mathrm{T}^{(\mathrm{f})}$ \\
$6.5^{(\mathrm{l})}$ & $2.2^{(\mathrm{g})}$ & $1.62^{(\mathrm{g})}$ & $0.9^{(\mathrm{j})}$ & $0.447+0.08 \times 10^{-3}\left(\mathrm{~V} / \mathrm{V}_{\mathrm{o}}\right) \mathrm{T}^{(\mathrm{f})}$ \\
\hline
\end{tabular}

A least squares fit to all but the three lowest points yields a zero-pressure bulk modulus of $\mathrm{K}_{0 \mathrm{~S}}=162( \pm 9)$ $\mathrm{GPa}\left(\mathrm{K}_{\mathrm{OS}}^{\prime}=4.7 \pm 0.3\right)$. This is in relatively good accord with the ultrasonically determined $K_{0 S} \sim 145( \pm 3) \mathrm{GPa}$ for pyrite [Simmons and Wang, 1971], thus substantiating the point that no major phase transition occurs under shock loading. However, we note that the highest pressure datum of Simakov et al. biases the fit toward too low a bulk modulus. For example, the best fit to only the present data yields $\mathrm{K}_{0 \mathrm{~S}}=174( \pm 7) \mathrm{GPa}$ (Figure 5). In this case, an equation of state of more than second order (Birch equation) is not statistically justifiable, so $\mathrm{K}_{\mathrm{OS}}=4, \xi_{\mathrm{S}}=0$ and $\mathrm{F}_{\mathrm{SH}}=174$ is a constant with strain.

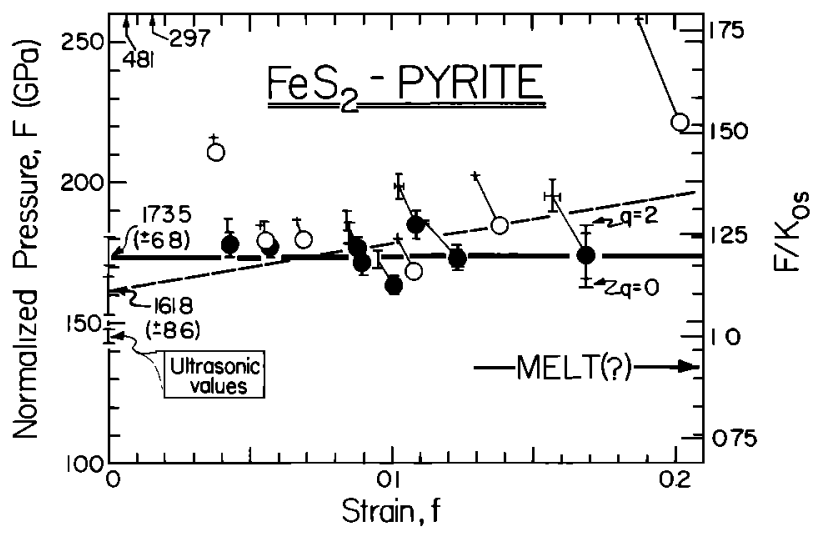

Fig. 5. Shock wave measurements on $\mathrm{FeS}_{2}$ displayed in terms of normalized pressure $F$ versus strain $f$. Reduced data $\left(F_{H S}, f_{3 H}\right)$ are shown by open [Simakov et al., 1974] and closed (present data) symbols which are tied to the raw Hugoniot points $(F, f)$ shown as crosses and unadorned error bars. Two lowest present points lie off the plot at $\mathrm{F}_{\mathrm{HS}}=481$ and $297 \mathrm{GPa}$. The larger error bars on $\mathrm{F}_{\mathrm{HS}}$ (evident only at large strains) illustrate the additional uncertainty caused by letting $q$ vary from 0 to 2 . An unweighted fit to all but the three lowest points yields the dashed line $\left(\mathrm{K}_{0 \mathrm{~S}}=161.8 \pm 8.6 \mathrm{GPa}\right)$, whereas a weighted fit to all but the two lowest present points yields the solid line $\left(\mathrm{K}_{0 \mathrm{~S}}=173.5 \pm 6.8 \mathrm{GPa}, \mathrm{K}^{\prime}{ }_{0 \mathrm{~S}}=4\right.$ assumed).
Regardless of how one fits the data, it is clear that the shock measurements systematically yield $F_{S H}$ larger than the ultrasonic value of $145 \mathrm{GPa}$ (Figure 5). The best fit to the present data results in a bulk modulus approximately $20 \%$ larger than the range of ultrasonic values, which is well outside the limits of estimated uncertainties. In addition, hydrostatic-compression measurements yield an isothermal value $K_{0 T}=143 \mathrm{GPa}$ that agrees with the ultrasonic measurements [Jephcoat and Olson, 1987]. Thus there is strong evidence that the Hugoniot data do not reflect the properties of the zero-pressure structure of pyrite, as determined by the ultrasonic and hydrostaticcompression experiments.

In order to better understand the nature of this discrepancy, it is worth examining the forms of (9) - (17) and the reduction of Hugoniot data in the $F$ - $f$ plane. In Figure 6 the thermal correction to the Hugoniot strain is illustrated for a range of $\gamma$ encompassing the values that are encountered in practice. In all cases, the corrected strains $\mathbf{f}_{3 \mathrm{H}}$ and $\mathbf{f}_{4 \mathrm{H}}$ are larger than the raw (Hugoniot) value $\mathrm{f}$, but the thermal correction is typically less than $20 \%$ up to a strain of 0.2 . In particular, it is evident that for $\gamma \leq 1.5$ (high-pressure value), $\mathrm{f}_{4 \mathrm{H}} \stackrel{\sim}{=} \mathrm{f}_{3 \mathrm{H}}$ to within $5 \%$ up to a strain $\mathrm{f}=0.2$. This justifies our current treatment of (10) as a polynomial expansion of $F_{\mathrm{HS}}$ in terms of $f_{3 \mathrm{H}}$ alone, when considering the pyrite data. Clearly, there is no evidence for curvature in the $F_{H S}$ reduced values in Figure 5 except possibly if one includes the highest pressure datum

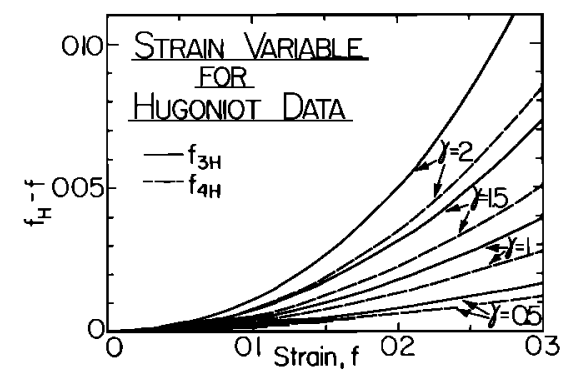

Fig. 6. Difference between the reduced strain $f_{H}$ derived from (13) and (14) and the measured strain $f$ from (9) is shown as a function of strain and Gruneisen parameter $\gamma$ (taken to be constant for each curve). 


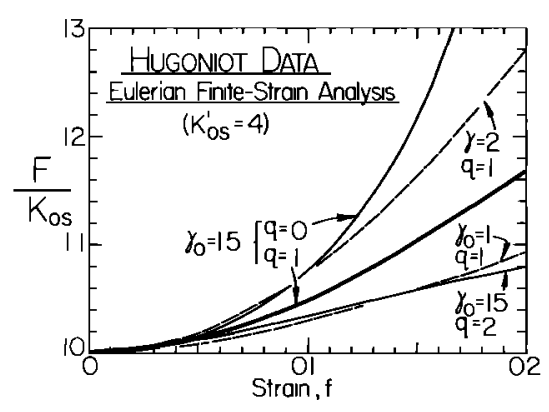

Fig. 7. Predicted Hugoniots shown as the nondimensional ratio $F / K_{0 s}$ versus strain $f$. The heavy curve is for a material described by a second-order $\left(K_{0 S}^{\prime}=4\right)$ Eulerian finite-strain equation of state with $\gamma_{0}=1.5$ and $q=1$, and lighter (solid and dashed) curves illustrate the effects of varying $\gamma_{0}$ between 1 and 2 or $q$ between 0 and 2 (see (18)). In all cases, the isentrope lies along the axis $F / K_{0 S}$ $=1$.

of Simakov et al. As argued above, this point is perhaps best left out of the analysis. In either case, a linear (thirdorder) form of $F_{H S}$ in $f_{3 H}$ is the most that is justified by the Hugoniot data. Ignoring the highest point, or considering only the present data, yields $F_{H S}$ being statistically independent of $\mathrm{f}_{3 \mathrm{H}}$, thus implying that a second-order equation of state is adequate $\left(\mathrm{K}_{0 \mathrm{~S}}=4\right)$.

A second-order equation of state is given by $\mathrm{F}_{\mathrm{HS}} / \mathrm{K}_{\mathrm{0S}}=$ 1. The relation of this isentrope to the raw Hugoniot is illustrated in Figure 7 . Here, $\gamma_{0}=1.5, q=1$ are taken as typical values, but the effect of varying $\gamma_{0}(1$ to 2$)$ and $q$ $(0$ to 2$)$ is also shown. For the parameters given, this figure summarizes how raw Hugoniot data ( $F$ versus $f$ ) would be reduced to the isentrope $\mathbf{F}_{\mathrm{HS}}=\mathrm{K}_{\mathbf{0 S}}=$ const when applying the thermal correction inherent in the MieGrüneisen formulation. For example, at a strain of 0.2 the normalized Hugoniot pressure $F$ is corrected downward by $17 \%$ of $\mathrm{K}_{0 \mathrm{~S}}\left(\gamma_{0}=1.5, \mathrm{q}=1\right.$, second-order equation of state). The uncertainties in the reduced values are therefore only a fraction of this $17 \%$ correction. Although these uncertainties increase with pressure (larger error bars with increasing strain in Figure 5), they remain small relative to the discrepancy between the Hugoniot-derived $K_{0 s}$ and ultrasonic bulk modulus for the pyrite data.

$U_{p}$ to this point, the effects of phase transitions have been ignored. The most important change due to a transition is in $f$, which in turn changes $f_{3 H}, F$, and $F_{H S}$ via (13), (17), and (11). By comparison, $\Delta \mathrm{F}_{\mathrm{tr}}$ gives only a small offset to $F_{H S}$ in (10). This can be seen from characteristic values of $\mathrm{E}_{\mathrm{tr}} / \mathrm{V} \sim 2 \mathrm{GPa}$ [e.g. Davies and Gaffney, 1973], which is of the order of $10^{-2} K_{02}$ for minerals. As the remaining terms in (12) amount to a factor of about 1 to 2 , $\Delta F_{t r}$ is expected to change $F_{H S}$ by only a few percent. Thus $\Delta F_{t r}$ can be safely ignored in the present discussion.

Assuming that the phase along the Hugoniot (indicated by subscript 2) is described by a second-order equation of state, $F_{2}=$ const independent of $f_{2}$. The observed strain is now given by

$$
\mathrm{f}=\left[\left(1+2 \mathrm{f}_{2}\right)\left(\mathrm{V}_{01} / \mathrm{V}_{02}\right)^{2 / 3}-1\right] / 2
$$

where the zero-pressure crystal volume of the initial phase is labelled by subscript 01 for clarity. Substituting (19) into (17) and (11) yields the observed normalized pressure including the phase transition. The resulting Hugoniots for volume ratios $0.95 \leq \mathrm{V}_{01} / \mathrm{V}_{02} \leq 1.05$ are summarized in Figure 8, which is an F- $\mathrm{f}$ plot showing the effects of a phase transition on the basic Hugoniot of Figure 7 (second-order adiabat, $\gamma_{0}=1.5, \mathrm{q}=1$, with $\mathrm{E}_{\mathrm{tr}}=\Delta \mathrm{F}_{\mathrm{tr}}$ $=0$ ).

What is clearly evident from Figure 8 is that a transition with a volume change of only a few percent can change the observed $F$ by several tens of percent. For example, a volume change of $5 \%$ shifts the normalized pressure by about $40 \%$ at a strain of 0.1 . In comparison, the thermal correction from Hugoniot to isentrope is only $5 \%$ at the same strain, and its uncertainty is likely to be much smaller (Figure 7). The change of $F$ has the same sign as the volume change on transformation, and its magnitude increases drastically at small strains. That is, even a small increase in volume across a transition makes the equation of state appear anomalously stiff, and hence it significantly increases $\mathrm{F}$ at small strains.

Returning to Figure 5, it appears that the simplest interpretation of the reduced Hugoniot data $\left(F_{H S}\right.$ versus $\left.f_{H}\right)$ is that they reflect the properties of a different phase than the initial pyrite. That $F_{H S}$ is systematically larger than the ultrasonic $K_{0 S}$ requires the new phase to be of larger volume (by up to $\sim \mathbf{2}$ or $3 \%$ from Figure 8 ) or to be less compressible (by up to $\mathrm{F}_{\mathrm{HS}} / \mathrm{K}_{0 \mathrm{~S}}-1 \sim 20 \%$ ) than pyrite. The alternative possibility that $\Delta \mathrm{F}_{\mathrm{tr}}$ is responsible was shown above to be implausible: a strongly exothermic reaction $\left(E_{t r}<0\right)$ would increase $F$ but only by a few percent, rather than $\sim 20 \%$.

Although there is a trade-off between contributions from changes in volume, bulk modulus, and internal energy, it seems that most if not all of the discrepancy between the $F_{H S}$ values and the ultrasonic $K_{0 S}$ of pyrite can be accounted for by a small volume increase across a shock-induced transition. What is interesting is that such a transition could not be induced by pressure alone, because transformations caused by pressure must thermodynamically involve a volume decrease [e.g. Goodstein, 1975]. Therefore the temperature rise along the Hugoniot must be involved in creating what can be thought of as a high-temperature phase of $\mathrm{FeS}_{2}$. Recognizing that pyrite melts incongruently at $1016 \mathrm{~K}$ at zero pressure [Kullerud, 1966], it is conceivable that partial or complete fusion explains the results of Figure 5.

The excess volume increases of up to $\sim 4 \%$ observed upon isentropic release from pressures in the range 28 to $182 \mathrm{GPa}$ suggest that the Hugoniot states are partially, rather than completely melted. Additional melting appears to take place upon isentropic release from this pressure range.

\section{Application to the Earth's Core}

Our tactic in this section is to construct an equation of state for molten iron and pyrite and compare these with the seismic models for the molten outer core.

The inner core is not treated here. Recently it has been modeled by Anderson [1986] and Jephcoat and Olson [1987], who conclude it is pure iron or contains a few percent of a light element, respectively.

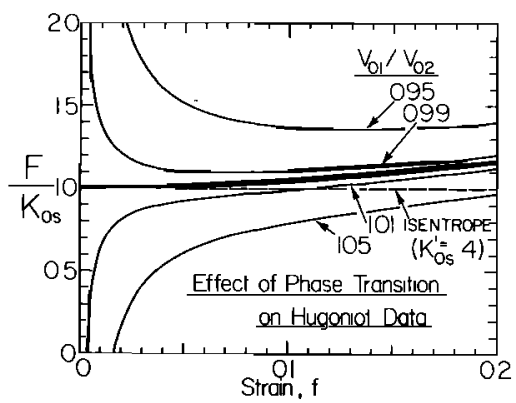

Fig. 8. Effect of a phase transition on the Hugoniot is displayed as nondimensional $\mathrm{F} / \mathrm{K}_{0 \mathrm{~S}}$ versus strain, for ratios of zero-pressure volume ranging between $\mathrm{V}_{01} / \mathrm{V}_{02}=0.95$ and 1.05 (subscripts 1 and 2 refer to the initial sample and the phase achieved along the Hugoniot). In all cases, $\Delta F_{t_{r}}$ in (10) is set to zero, and a second-order equation of state with $\gamma_{0}=1.5, q=1$ is assumed. The bold curve is for $\mathrm{V}_{01} / \mathrm{V}_{02}=1$, and it is identical to the bold curve in Figure 7; the corresponding isentrope is shown by the dashed line. 


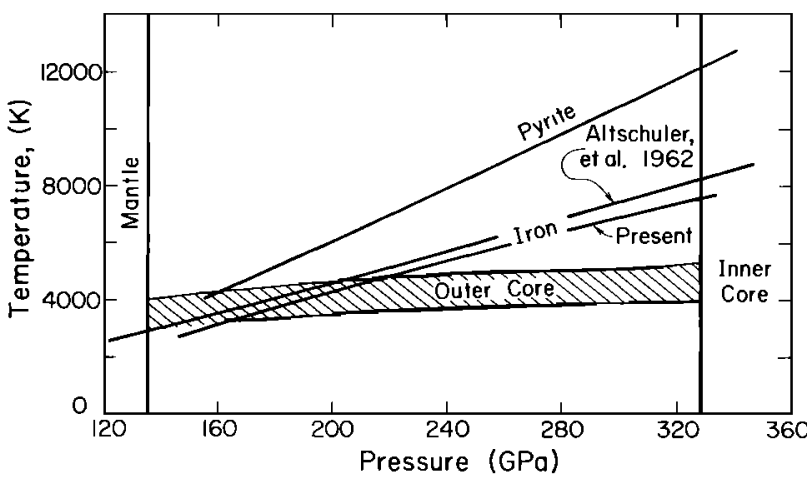

Fig. 9. Shock temperature versus shock pressure for pyrite and iron. Present calculation of shock temperatures for iron are shown for McQueen et al. [1970], and Brown and McQueen [1986] equation of state. Al'tshuler et al. [1962] shock temperatures are also shown.

Birch-Murnaghan parameters for iron over the pressure ranges indicated were obtained using both the McQueen et al. 1970] and Al'tshuler et al. [1962] shock wave data set (Table 3). It should be recognized that only in the case of iron are there definitive data [Brown and McQueen, 1986; Williams et al., 1987], which specify which portion of the high-pressure phase Hugoniot corresponds to the liquid (above $\sim 250 \mathrm{GPa}$ ). The analysis of Jeanloz [1979] for the parameters $\gamma_{0}$ and $q$, based on shock data for porous iron, however, most certainly reflect the properties of liquid. The trajectory of the iron Hugoniot in the pressuretemperature phase diagram has been recently discussed both by Brown and McQueen [1986] and Anderson [1986]. In order to estimate the shock pressures at which the pyrite Hugoniot is likely to go in to the liquid field, we calculated shock temperatures from the formula [Ahrens, 1979]

$$
\begin{gathered}
\mathrm{T}_{\mathrm{s}}=298 \exp \left[\gamma_{\mathrm{o}} \rho_{\mathrm{o}}^{\mathrm{q}}\left(\mathrm{V}_{\mathrm{o}}^{\mathrm{q}}-\mathrm{V}^{\mathrm{q}}\right) / \mathrm{q}\right] \\
\mathrm{T}_{\mathrm{H}}=\left\{-3 \mathrm{R}+\left[9 \mathrm{R}^{2}+2 \beta_{\mathrm{o}}\left(\mathrm{V} / \mathrm{V}_{\mathrm{o}}\right)\left(3 \mathrm{RT}_{\mathrm{s}}+\beta_{\mathrm{o}}\left(\mathrm{V} / \mathrm{V}_{\mathrm{o}}\right) \mathrm{T}_{\mathrm{s}}{ }^{2} / 2\right.\right.\right. \\
\left.\left.\left.\left.+\left(\mathrm{P}_{\mathrm{H}}-\mathrm{P}_{\mathrm{s}}\right)(\mathrm{V} / \gamma)\right)\right]^{1 / 2}\right\} / \mid \beta_{\mathrm{o}}\left(\mathrm{V} / \mathrm{V}_{\mathrm{o}}\right)\right]
\end{gathered}
$$

where $T_{s}$ is the temperature along the principal isentrope at volume $\mathrm{V}$ and $\mathrm{T}_{\mathrm{H}}$ is the Hugoniot temperature. Equation (21) is derived for a material behaving with a specific heat which is the sum of lattice modes (3R) plus an electronic term $\beta_{\mathrm{o}}\left(\mathrm{V} / \mathrm{V}_{\mathrm{o}}\right) \mathrm{T}$ as specified in Table 3 . The resulting shock temperature calculations are shown for

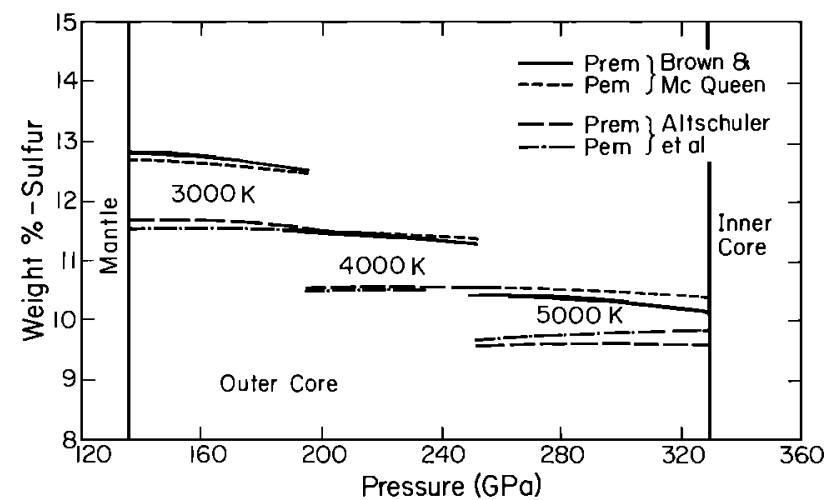

Fig. 10. Weight percent sulfur versus pressure for various isotherms and iron equations of state of McQueen et al. [1970], Brown and McQueen [1986], and Al'tshuler et al. 1962]. Curves are calculated for both PREM and PEM core models. Differences between two iron equations of state yield a difference of $\sim 1 \%$ in apparent weight percent sulfur.

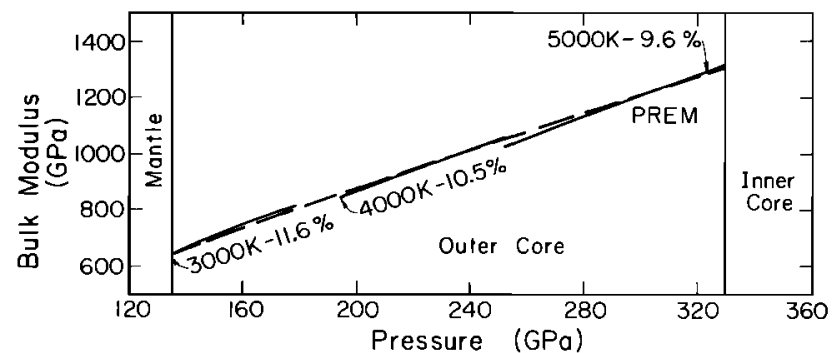

Fig. 11. Bulk modulus versus pressure in the outer core for 3000,4000 , and $5000 \mathrm{~K}$ isotherms constrained by PREM earth model. Average value of sulfur content in percent is indicated for each isotherm calculated with the Al'tshuler et al. [1962] iron equation of state.

pyrite and for the above equation-of-state formulation for iron in Figure 9. The latter calculation is comparable to that obtained by Al'tshuler et al. [1962] using a similar thermal formulation but a different equation of state. Since pyrite is more compressible, the calculated shock temperatures for pyrite are not unexpectedly substantially higher than iron. These values would be reduced perhaps by $\sim 500$ to $700 \mathrm{~K}$ if a fusion energy (unknown) were incorporated in the temperature calculation via $\mathrm{E}_{\mathrm{TR}}$ in (8). We infer from both the excess volume upon release and the normalized volume fits of Figures 5 and 8 that the pyrite Hugoniot probably represents material in the liquid state over much of the pressure range of the outer core. We note that at zero pressure the $\mathrm{FeS}-\mathrm{FeS}_{2}$ eutectic (at $1356 \mathrm{~K}$ ) occurs at substantially lower temperature than the iron melting point of $1812 \mathrm{~K}$. Also since the iron Hugoniot crosses its fusion curve at $250 \mathrm{GPa}$, we might expect that pyrite will also be molten in this pressure range along the Hugoniot. The effect of the energy of melting on the present Hugoniot temperatures is such that they will be too high in the melt regime by $\sim 550^{\circ} \mathrm{C}$

In order to calculate the mass fraction of sulfur which could account for the density deficit, relative to pure iron in the liquid outer core, specific volumes of iron, and $\mathrm{FeS}_{2}$ at temperatures of 3000,4000 , and $5000 \mathrm{~K}$ at a series of pressures corresponding to those of the outer core (135.8 to $328.9 \mathrm{GPa}$ ) were calculated from

$$
\left(\mathrm{P}_{\mathrm{T}}-\mathrm{P}_{\mathrm{s}}\right) \frac{\mathrm{V}}{\gamma}=3 \mathrm{R}\left(\mathrm{T}-\mathrm{T}_{\mathrm{s}}\right)+\frac{1}{2} \beta_{\mathrm{o}} \frac{\mathrm{V}}{\mathrm{V}_{\mathrm{o}}}\left(\mathrm{T}^{2}-\mathrm{T}_{\mathrm{s}}^{2}\right)
$$

where $P_{s}$ and $T_{s}$ are given by (17) and (20). The independent variables for this calculation were the isothermal temperature, $T$, and $P_{T}$, the pressure at which the mass fraction $\mathrm{S}$ was to be calculated. The specific volume of each phase was then calculated by solving (22) via the NewtonRaphson method.

Since both the temperature and composition of the liquid core are unconstrained, we consider core composition in terms of three isotherms (Figure 10) in specific volume mixing calculations. The isotherms chosen, 3000, 4000, and $5000 \mathrm{~K}$, are based on the thermal core models of Stacey [1977] and Stevenson [1981] and the application of (20) Using the Grüneisen parameters of iron for calculating the isentropic (adiabatic) temperature rise in the outer core yields values of $4010 \mathrm{~K}$ and $5346 \mathrm{~K}$ at the inner core boundary (ICB) starting with 3000 and $4000 \mathrm{~K}$ at the core mantle boundary (CMB). The steps in the density and bulk modulus curve (Figures 10-12) correspond to different isotherms. The core temperature, of course, varies smoothly with depth, rising some 1000 to $1500 \mathrm{~K}$. Here we assume densities of 9.903 and $12.17 \mathrm{Mg} / \mathrm{m}^{3}$ at the CMB and base of the outer core, respectively, from the preliminary reference earth model (PREM) of Dziewonski and Anderson [1981]. Calculating the specific volume of pyrite $\mathrm{V}_{\mathrm{py} y}$, iron $\mathrm{V}_{\mathrm{Fe}}$, and the earth $\mathrm{V}_{\text {ea }}$, using either the PREM or preliminary earth model PEM [Dziewonski et al., 1975] for $V_{e q}$ yields the mass [raction of pyrite at a given temperature as 


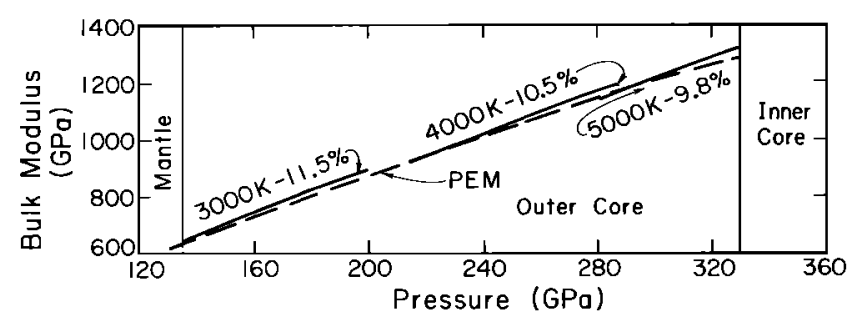

Fig. 12. Bulk modulus versus pressure for the outer core of the earth for isotherms at 3000,4000 , and $5000 \mathrm{~K}$. PEM earth model was used. Percent sulfur shown is average for isotherm utilizing McQueen et al. [1970] and Brown and McQueen [1986] iron equation of state.

$$
\mathrm{Y}=\left(\mathrm{V}_{\mathrm{ea}}-\mathrm{V}_{\mathrm{Fe}}\right) /\left(\mathrm{V}_{\mathrm{pyr}}-\mathrm{V}_{\mathrm{Fe}}\right)
$$

the mass fraction sulfur $\mathrm{X}$ is $0.534 \mathrm{Y}$. As can be seen in Figure 10, not only does the assumed temperature affect the calculated percent $S$ in the outer core, but the differences between the Al'tshuler et al. [1962] and McQueen et al. [1970] equation of state of iron correspond to an equivalent of $\sim 1000 \mathrm{~K}$ for each $\mathrm{T}$. Notably the differences between the PREM and PEM affect the resultant mass fraction of $S$ in only a minor way. Since we have not taken into account the heat of fusion, the isothermal volume of iron is slightly too small, as the thermal correction from the Hugoniot is too large. Therefore (23) gives a slight overestimate of $\mathrm{S}$ content in the core.

Ideally one might expect a nearly constant value of the weight percent with pressure if the outer core is, on the average, in a state of slight superadiabaticity and is convecting.

In order to further sort out the effect of temperatures, two models for the iron equations of state and slightly different earth models on the weight percent $S$, we have also examined the bulk modulus calculated for the percentage of sulfur which the above range of models predicts. Jeanloz [1979] pointed out the bulk modulus in the outer core was some $\sim 12 \%$ lower than that of iron. The bulk modulus of a mixture of pyrite and liquid iron was then calculated using the Voigt-Reuss-Hill approximation [Watt et al., 1976]. Fitting the seismic data for the bulk modulus in the 3000 to $5000 \mathrm{~K}$ range using the PREM model, the Al'tshuler et al. iron equation of state and combined with the present pyrite equation of state yields the mass fractions, $\mathrm{S}$, shown in Figure 11. The calculated percent $\mathrm{S}$ varies from $11.6 \%$ to $9.6 \%$ as the assumed temperature increases by $\sim 2000 \mathrm{~K}$ from 3000 to $5000 \mathrm{~K}$ throughout the outer core. A fit which demands a more likely adiabatic temperature rise with depth in the core and a percentage $S$ content, which is more nearly constant, can also be achieved by fitting simultaneously both the density and bulk moduli of the core with pressure, again using the Al'tshuler et al. equation of state for iron and the PEM model (Figure 12). The temperature rise with depth in the core inferred from this model is $\sim \mathbf{1 4 0 0} \mathrm{K}$, whereas the variation of apparent $S$ content with depth is from $11.5 \%$ to $9.8 \%$. Both fits are close to the $10( \pm 4) \% \mathrm{~S}$ content inferred by Brown et al. [1984] on the basis of density using the high-pressure phase of pyrrhotite and iron equations of state at similar temperatures.

\section{Discussion}

An issue not yet addressed is the initial spin electronic states of $\mathrm{FeS}_{2}$ (pyrite) versus pyrrhotite or troilite (FeS). Vaughan and Craig [1978] point out that in pyrite the 3-d, orbital electron configuration is initially in the low-spin state, whereas in $\mathrm{Fe}_{1-\mathrm{x}} \mathrm{S}$ and $\mathrm{FeS}$ these start out with the high-spin configuration, and depending on details of the defect chemistry, the latter transform to phases with lowspin 3-d orbital configurations with increasing pressure. Thus both the phase changes in FeS and their absence in $\mathrm{FeS}_{2}$ have some rationale.
Since the release isentrope experiments indicate a greater volume is achieved than can be readily explained with a plausible Grüneisen ratio, it appears that transition to a slightly lower density $(\sim 1 \%)$ phase is occurring upon pressure release. Also we observe the shock wave data fit the zero-pressure bulk moduli exactly in the $F$ versus $f$ analysis if a slight increase in apparent zero-pressure volume $(2-3 \%)$ is assumed. If we associate both results, it may be that the shock wave data indicate that shockinduced melting is occurring ( $F-f$, results), whereas upon unloading, additional pressure-release melting takes place. Further research on the high-pressure, high-temperature phase diagram of $\mathrm{Fe}_{2} \mathrm{~S}$ should clarify the situation.

With regard to application of the present results to constraining the possible sulfur content of the earth's outer liquid core, we have found that the shock wave data for pyrite probably represent the properties of the liquid. In the case of iron, the case for the shock data representing the properties of the liquid above $250 \mathrm{GPa}$ is very strong (as inferred from sound speed and temperature shock measurements [Brown and McQueen, 1986; Williams et al., 1987]).

When the present data for pyrite are used in conjunction with iron data to fit the seismically derived pressuredensity and pressure/bulk modulus profile of the outer core, several conclusions may be drawn.

1. Good agreement between the shock wave equation of state and the seismic data is obtained for temperatures of $\sim 3000 \mathrm{~K}$ at the core-mantle boundary extending to 4400 $K$ at the outer core/inner core boundary. For this thermal model a calculated sulfur content of $11 \pm 2 \%$ is obtained in agreement with the results inferred by Anderson [1977], Ahrens [1979], and Brown et al. [1984].

2. Thermal and composition models of the outer core derived here are consistent with adiabatic variation of temperatures through the core by $\sim 1500 \mathrm{~K}$. However, the level of temperatures within the range $\sim 3000-5000 \mathrm{~K}$ are at least $\sim 1500 \mathrm{~K}$ lower than the $\sim 6600 \pm 500 \mathrm{~K}$ inferred by Williams et al. [1987] at the outer core/inner core boundary. This discrepancy could imply a much greater melting point depression than previously thought, which cannot be ruled out.

3. The conclusions concerning sulfur content change little using different core seismic models. However, the difference between the Brown and McQueen [1986] and Al'tshuler et al. [1962] data for iron translates in to about a $1 \%$ difference in apparent sulfur content. Also of concern is the consistent apparent decrease by $21 / 2 \%$ in equivalent weight percent sulfur, in going from the core-mantle boundary to inner core/outer core boundary found in all combinations of seismic and equation-of-state models. Although such a compositional variation is not physically impossible, it may represent presently unrecognized inaccuracies in present Earth and material models.

\section{Appendix: Uncertainties in Normalized Shock Pressure Finite-Strain Analysis}

The following quantites are assumed to be either experimentally measured or estimated, and hence each can be assigned a standard deviation(s): $P_{\mathrm{H}}, \mathrm{V}, \mathrm{V}_{\mathrm{o}}, \mathrm{V}_{\mathrm{oo}}, \gamma, \mathrm{q}, \mathrm{E}_{\mathrm{TR}}$. For purposes of error analysis we assume that the dependent variable defined in terms of the quantities in (10) is

$$
\mathrm{F}_{\mathrm{HS}}^{\prime}=\mathrm{F}_{\mathrm{HS}}+\Delta \mathrm{F}_{\mathrm{tr}}
$$

Paralleling the treatment in Heinz and Jeanloz [1984], we write, dropping the subscripts,

$$
\begin{gathered}
s^{2}\left(F^{\prime}\right)^{2}=\left(\frac{\partial F^{\prime}}{\partial f}\right)^{2} s^{2}(f)+\left(\frac{\partial F^{\prime}}{\partial \gamma}\right)^{2} s^{2}(\gamma)+\left[\frac{\partial F^{\prime}}{\partial P_{H}}\right)^{2} s^{2}\left(P_{H}\right) \\
+\left(\frac{\partial F^{\prime}}{\partial E_{t r}}\right)^{2} s^{2}\left(E_{t r}\right)+\left(\frac{\partial F^{\prime}}{\partial V_{o}}\right)^{2} s^{2}\left(V_{o}\right) \\
+\left(\frac{\partial F^{\prime}}{\partial V_{o o}}\right)^{2} s^{2}\left(V_{o o}\right)
\end{gathered}
$$


where if we consider the first term in (A2), it in turn is the sum of two terms

$$
\frac{\partial \mathrm{F}^{\prime}}{\partial \mathrm{f}}=\frac{\partial \mathrm{F}_{\mathrm{HS}}}{\partial \mathrm{f}}+\frac{\partial \Delta \mathrm{F}}{\partial \mathrm{f}}
$$

where the first term is

$$
\begin{gathered}
\frac{1}{\mathrm{P}_{\mathrm{H}}} \frac{\partial \mathrm{F}}{\partial \mathrm{f}}=-\mathrm{R} \gamma /\{2 \mathrm{f}(1+2 \mathrm{f})[1+(2-1.5 \gamma) \mathrm{f}]\}^{-1} \\
-\left\{\left[1-0.5 \gamma(2 \mathrm{f}+1)^{3 / 2} \mathrm{R}+0.5 \gamma \mid\left\{(1+2 \mathrm{f})^{-1}\left[3 \mathrm{f}+(6-4.5 \gamma) \mathrm{f}^{2}\right]\right.\right.\right. \\
+[1+(4-3 \gamma) \mathrm{f}]\}\} /\left\{3 \mathrm{f}^{2}(1+2 \mathrm{f})^{3 / 2}\{1+(2-1.5 \gamma) \mathrm{f}\}^{2}\right\}
\end{gathered}
$$

and the second is

$$
\frac{\partial \Delta \mathrm{F}}{\partial \mathrm{f}}=-\mathrm{E}_{\mathrm{TR}} \gamma[3 \mathrm{f}[1+(2-1.5 \gamma) \mathrm{f}]]^{-2}(3+12 \mathrm{f}-9 \gamma \mathrm{f}) / \mathrm{V}_{\mathrm{o}}(\mathrm{A} 5)
$$

Since

$$
\mathrm{s}^{2}(\mathrm{f})=\left(\frac{\partial \mathrm{f}}{\partial \mathrm{V}}\right)^{2} \mathrm{~s}^{2}(\mathrm{v})+\left(\frac{\partial \mathrm{f}}{\partial \mathrm{V}_{\mathrm{o}}}\right)^{2} \mathrm{~s}^{2}\left(\mathrm{~V}_{\mathrm{o}}\right)
$$

we write

$$
\begin{aligned}
& \frac{\partial \mathrm{f}}{\partial \mathrm{V}}=-\left(\mathrm{V}_{\mathrm{o}} / \mathrm{V}\right)^{5 / 3} /\left(3 \mathrm{~V}_{\mathrm{o}}\right) \\
& \frac{\partial \mathrm{f}}{\partial \mathrm{V}_{\mathrm{o}}}=\left(\mathrm{V}_{\mathrm{o}} / \mathrm{V}\right)^{2 / 3} /\left(3 \mathrm{~V}_{\mathrm{o}}\right)
\end{aligned}
$$

The coefficient of the first term of (A2) can now be calculated using (A3)-(A8). The coeflicient of the second term of (A2) is also given by two terms:

$$
\begin{gathered}
\frac{\partial \mathrm{F}^{\prime}}{\partial \gamma}=\frac{\partial \mathrm{F}_{\mathrm{HS}}}{\partial \gamma}+\frac{\partial \Delta \mathrm{F}}{\partial \gamma} \\
\frac{1}{\mathrm{P}_{\mathrm{H}}} \frac{\partial \mathrm{F}}{\partial \gamma}=\left\{[1+(2-1.5 \gamma) \mathrm{f}]\left[-0.5(2 \mathrm{f}+1)^{3 / 2} \mathrm{R}+0.5\right]\right. \\
\left.+(1.5)\left(1-0.5 \gamma(2 \mathrm{f}+1)^{3 / 2} \mathrm{R}+0.5 \gamma\right) \mathrm{f}\right\} / \\
\left\{3 \mathrm{f}(1+2 \mathrm{f})^{3 / 2}[1+(2-1.5 \gamma) \mathrm{f}]^{2}\right\}
\end{gathered}
$$

and

$$
\begin{gathered}
\frac{\partial \Delta \mathrm{F}}{\partial \gamma}=\mathrm{E}_{\mathrm{TR}}\left[3 \mathrm{~V}_{\mathrm{o}} \mathrm{f}[1+(2-1.5 \gamma) \mathrm{f} \mid]^{-1}\right. \\
+\mathrm{E}_{\mathrm{TR}} \gamma /\left\{2 \mathrm{~V}_{\mathrm{o}}[1+(2-1.5 \gamma) \mathrm{f}]^{2}\right\}
\end{gathered}
$$

The coefficient of the third term of (A2) is given by

$$
\frac{\partial \mathrm{F}^{\prime}}{\partial \mathrm{P}_{\mathrm{H}}}=\frac{\partial \mathrm{F}_{\mathrm{HS}}}{\partial \mathrm{P}_{\mathrm{H}}}+\frac{\partial \Delta \mathrm{F}}{\partial \mathrm{P}_{\mathrm{H}}}=\frac{\mathrm{F}_{\mathrm{HS}}}{\mathrm{P}_{\mathrm{H}}}
$$

The coeflicient of the fourth term of (A2) is given by

$$
\frac{\partial \mathrm{F}^{\prime}}{\partial \mathrm{E}_{\mathrm{TR}}}=\frac{\partial \mathrm{F}_{\mathrm{HS}}}{\partial \mathrm{E}_{\mathrm{TR}}}+\frac{\partial \Delta \mathrm{F}}{\partial \mathrm{E}_{\mathrm{TR}}}=\frac{\Delta \mathrm{F}}{\mathrm{E}_{\mathrm{TR}}}
$$

The coefficient of the fifth term of (A2) is given by

$$
\begin{gathered}
\frac{\partial \mathrm{F}^{\prime}}{\partial \mathrm{V}_{\mathrm{o}}}=0.5 \mathrm{P}_{\mathrm{H}} \gamma(2 \mathrm{f}+1)^{3 / 2} \mathrm{~V}_{\mathrm{oo}} /\left\{\mathrm{V}_{\mathrm{o}}^{2}[1+(2-1.5 \gamma) \mathrm{f}] 3 \mathrm{f}(1+2 \mathrm{f})^{3 / 2}\right\} \\
-\mathrm{E}_{\mathrm{TR}} \gamma\left[3 \mathrm{~V}_{\mathrm{o}}^{2} \mathrm{f}[1+(2-1.5 \gamma) \mathrm{f}]\right]^{-1}
\end{gathered}
$$

Finally the coefficient of the sixth term of (A2) is given by

$$
\begin{gathered}
\frac{\partial \mathrm{F}^{\prime}}{\partial \mathrm{V}_{\mathrm{oo}}}=-\mathrm{P}_{\mathrm{H}} \gamma(2 \mathrm{f}+1)^{3 / 2} /\left\{6 \mathrm{~V}_{\mathrm{o}} \mathrm{f}[1+(2-1.5 \gamma) \mathrm{f}]\right. \\
\left.(1+2 \mathrm{f})^{3 / 2}\right\}
\end{gathered}
$$

The uncertainties in the independent variable of $(10), f_{3 H}$, are specified by

$$
\mathrm{s}^{2}\left(\mathrm{f}_{3 \mathrm{H}}\right)=\left(\frac{\partial \mathrm{f}_{3 \mathrm{H}}}{\partial \Gamma}\right)^{2} \mathrm{~s}^{2}(\mathrm{f})+\left(\frac{\partial \mathrm{f}_{3 \mathrm{H}}}{\partial \gamma}\right)^{2} \mathrm{~s}^{2}(\gamma)
$$

where

$$
\frac{\partial \mathrm{f}_{3 \mathrm{H}}}{\partial \mathrm{f}}=\frac{1+\mathrm{f}(4-2 \gamma)}{1+2 \mathrm{f}-1.5 \gamma \mathrm{f}}-\frac{\mathrm{f}[1+(2-\gamma) \mathrm{f}](2-1.5 \gamma)}{(1+2 \mathrm{f}-1.5 \gamma \mathrm{f})^{2}}
$$

and

$$
\frac{\partial \mathrm{f}_{3 \mathrm{H}}}{\partial \gamma}=\frac{1.5 \mathrm{f}^{2}(1+(2-\gamma) \mathrm{f})-\mathrm{f}^{2}(1+2 \mathrm{f}-1.5 \gamma \mathrm{f})}{(1+2 \mathrm{f}-1.5 \gamma \mathrm{f})^{2}}
$$

The $\mathrm{s}^{2}(\mathrm{f})$ term in (A16) is specified by (A6)-(A8). Also

$$
\begin{aligned}
& \mathrm{s}^{2}(\gamma)=\left(\mathrm{V} / \mathrm{V}_{\mathrm{o}}\right)^{2 \mathrm{q}^{2}}\left(\gamma_{\mathrm{o}}\right)+\left(\mathrm{q} \gamma_{\mathrm{o}} / \mathrm{V}\right)^{2}\left(\mathrm{~V} / \mathrm{V}_{\mathrm{o}}\right)^{2 \mathrm{q}} \mathrm{s}^{2}(\mathrm{~V}) \\
& +\left(\gamma_{0} \mathrm{q} / \mathrm{V}_{\mathrm{o}}\right)^{2}\left(\mathrm{~V} / \mathrm{V}_{\mathrm{o}}\right)^{2 \mathrm{q}_{\mathrm{s}}{ }^{2}\left(\mathrm{~V}_{\mathrm{o}}\right)} \\
& +\left[\gamma \ln \left(\mathrm{V} / \mathrm{V}_{\mathrm{o}}\right)\right]^{2} \mathrm{~s}^{2}(\mathrm{q})
\end{aligned}
$$

Acknowledgments. Thomas J. Ahrens appreciates greatly the experimental assistance of C. Creaven, E. Gelle, and $M$. Long, and has profitted from technical discussions with D. Stevenson and G. Rossman, and the critical comments of two anonymous reviewers and of $D$. L. Anderson, M. Brown, and P. Watt on an earlier version of the manuscript. We thank A. P. Jephcoat for showing us his unpublished data. Supported under NSF grant EAR8219435. Division of Geological and Planetary Sciences, California Institute of Technology, contribution 4172 .

\section{Rererences}

Ahrens, T. J., High-pressure electrical behavior and equation of state of magnesium oxide from shock wave measurements, J.Appl. Phys, 37, 2532-2541, 1966.

Ahrens, T. J., Equations of state of iron sulfide and constraints on the sulfur content of the earth, J. Geophys. Res., 84, 985-998, 1979.

Ahrens, T. J., Shock wave techniques for geophysics and planetary physics, in Methods of Experimental Phrsics, edited by C. G. Sammis and T. L. Henyey, Academic, New York, in press, 1987.

Ahrens, T. J., and G. E. Duvall, Stress relaxation behind elastic shock waves in rock, J.Geophys. Res., 71, 43494360, 1966.

Ahrens, T. J., and J. T. Rosenberg, Shock metamorphism: Experiments on quartz and plagioclase, in Shock Metamorohism of Natural Materials, edited by B. M. French and N. M. Short, Pp. 59-81, Mono Book, Baltimore, Md, 1968.

Ahrens, T. J., J. H. Lower, and P. L. Lagus, Equation of state of forsterite, J. Geophys. Res, 76, 518-528, 1971.

Al'tshuler, L. V., A. A. Bakanova, and R. F. Trunin, Shock adiabats and zero isotherms of seven metals at high pressures, Sov. Phys. JETP, Engl. Transl. 15, 65-74, 1962.

Anderson, D. L., Composition of the mantle and core, Ann. Rev. Earth Planet. Sci., 5, 179-202, 1977.

Anderson, O. L., The earth's core and the phase diagram of iron, Philos. Trans. R. Soc. London. Ser. A, 306, 21-35, 1982.

Anderson, O. L., Properties of iron at the Earth's core conditions, Geophys. J. R. Astron. Soc. 84, 561-579, 1986.

Anderson, W. W., and T. J. Ahrens, Shock wave experiments on iron sulfide and sulfur in planetary cores (abstract), Lunar Planet. Sci., XVII, 11-12, 1986.

Asay, J. R., G. R. Fowles, G. E. Duvall, M. H. Miles, and R. F. Tinder, Effect of point defects on elastic decay in LiF, J. Appl. Phys., 43, 2132-2145, 1972.

Bassett, W. A., T. Takahashi, H. K. Mao, and J. S. Weaver, Pressure-induced phase transformation in $\mathrm{NaCl}$, J. Appl. Phys., 39, 319-325, 1968.

Batalov, V. A., V. A. Buzayeva, G. S. Telegin, and R. F. Trunin, Equations of state of metastable phase for

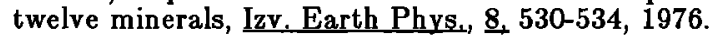


Birch, F., Elasticity and constitution of the earth's interior, J. Geophys. Res., 57, 227-286, 1952.

Birch, F., Finite strain isotherm and velocities for singlecrystal and polycrystalline $\mathrm{NaCl}$ at high pressures and $300 \mathrm{~K}, \mathrm{~J}$. Geophys. Res., 83, 1257-1268, 1978.

Brett, R., Chemical equilibration of the earth's core and upper mantle, Geochim. Cosmochim. Acta, 48, 1183$1188,1984$.

Bridgman, P. W., Linear compressions to $30,000 \mathrm{~kg} / \mathrm{cm}^{2}$, including relatively incompressible substances, Proc. Am. Acad. Arts Sci. 77, 187-234, 1949.

Brown, J. M., and R. G. McQueen, The equation of state for iron and the earth's core, in High Pressure Research in Geophysics, edited by S. Akimoto and M. H. Manghnani, pp. 611-624, Center for Academic Publications, Tokyo, 1982.

Brown, J. M., and R. G. McQueen, Phase transitions, Grüneisen parameter, and elasticity for shocked iron

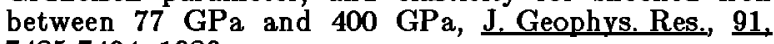
7485-7494, 1986.

Brown, J. M., T. J. Ahrens, and D. L. Shampine, Hugoniot data for pyrrhotite and the earth's core, J. Geophys. Res., 89, 6041-6048, 1984.

Davies, G. F., and E. S. Gaffney, Identification of highpressure phases of rocks and minerals from Hugoniot data, Geophys. J. R. Astron. Soc., 33, 165-183, 1973.

Donahue, T. M., and J. B. Pollack, Origin and evolution of the atmosphere of Venus, in Venus, edited by $D$. $M$. Hunter, L. Colin, T. M. Donahue, and V. I. Moroz, pp. 1003-1036, University of Arizona Press, Tucson, 1983.

Dziewonski, A. M., D. L. Anderson, Preliminary reference earth model, Phys. Earth Planet Inter, 25, 297-356, 1981.

Dziewonski, A. M., A. L. Hales, and E. R. Lapwood, Parametrically simple earth models consistent with geophysical data, Phys. Earth Planet. Inter. 10, 12-48, 1975.

Fukai, Y., and S. Akimoto, Hydrogen in the earth's core: Experimental approach, Proc. Jpn. Acad. 59B. 158-162, 1983.

Gold, T., and S. Soter, The deep-earth-gas hypothesis, Sci. Am. 154-161, June 1980.

Goodstein, D. L., States of Matter, 500 pp., Prentice-Hall, Englewood Cliffs, N. J., 1975.

Grady, D. E., Processes occurring in shock wave compression of rocks and minerals, in High Pressure Research: Applications in Geophysics, edited by M. H. Manghnani and S. Akimoto, pp. 389-438, Academic, New York, 1977

Hariya, $\mathrm{Y}_{.}, \mathrm{H}_{2} \mathrm{O}$ in the earth's interior, in Material Science of the Earth's Interior, edited by I. Sunagawa, pp. 463-476, Terra Scientific Publishers, Tokyo, 1984.

Heinz, D. L., and R. Jeanloz, The equation of state of the gold calibration standard, J.Appl. Phys., $\underline{55}$ 885-893, 1984.

Jackson, I., and T J. Ahrens, Shock wave compression of

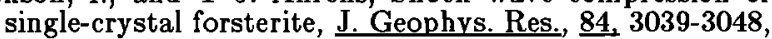
1979.

Jackson, I., and A. E. Ringwood, High pressure polymorphism of the iron oxides, Geophys. J. R. Astron. Soc., 67, 767-784, 1981.

Jacobs, J. A., The Earth's Core, 253 pp., Academic, New York, 1975

Jeanloz, R., Properties of iron at high pressures and the state of the core, J. Geophys. Res., 84, 6059-6069, 1979.

Jeanloz, R., and T. J. Ahrens, Pyroxenes and olivines: Structural implications of shock-wave data for high pressure phases, in High-Pressure Research, edited by M. Manghnani and S. Ákimoto, pp. 439-461, Academic, New York, 1977

Jeanloz, R., and T. J. Ahrens, Equations of state of $\mathrm{FeO}$ and $\mathrm{CaO}$, Geophys. J. R. Astron. Soc. 62, 505-528, 1980.

Jephcoat, A. P., and P. Olson, Is the inner core of the Earth pure iron? Nature, $\underline{325}, 332-335,1987$.

Jephcoat, A. P., H. K. Mao, and P. M. Bell, Pyrite:
Hydrostatic compression to $40 \mathrm{GPa}$, Eos Trans. AGU $\underline{64}, 847,1983$.

Jones, J. H., and M. J. Drake, An experimental approach to early planetary differentiation, Lunar Planet. Sci. XIII, 369-370, 1982.

Kullerud G., Phase relations in sulfide-type systems, in Handbook of Physical Constants, Mem., 97, edited by S. P. Clarke, Jr., pp. 323-344, Geological Society of America, Boulder, Colo., 1966.

Lange, M. A., and T. J. Ahrens, $\mathrm{FeO}$ and $\mathrm{H}_{2} \mathrm{O}$ and the homogeneous accretion of the earth, Earth Planet Sci. Lett., 71, 111-119, 1984.

Lange, M. A., and T. J. Ahrens, Shock-induced $\mathrm{CO}_{2}$ loss from $\mathrm{CaCO}_{3}$ : Implications for early planetary atmospheres, EarthPlanet. Sci. Lett., 77, pp. 409-418, Elsevier Science Publishers B.V., 1986.

Lewis, J. S., and R. G. Prinn, Planets and Their Atmospheres, Origin and Evolution, 470 pp., Academic, New York, 1984

Lyzenga, G., and T. J. Ahrens, The relations between the shock-induced free-surface velocity and post-shock density of solids, J.Appl. Phys., 49, 201-204, 1978.

Marsh, S. P. (Ed.), LASL Shock Hugoniot Data, 327 pp. University of California Press, Berkeley, 1980.

McQueen, R. G., S. P. Marsh, J. W. Taylor, J. N. Fritz, and $W$. J. Carter, The equation of state of solids from shock wave studies, in High Velocity Impact Phenomena, edited by R. Kinslow, pp. 294-419, Academic, New York, 1970.

Mitchell, A. C., and W. J. Nellis, Shock compression of aluminum, copper and tantalum, J.Apol. Phys, 52, 3363-3374, 1981

Murthy, V. R., Composition of the core and the early chemical history of the earth in The Early History of the Earth, edited by B. F. Windley, pp. 21-31, John Wiley, New York, 1976

Ohtani, E., and A. E. Ringwood, Composition of the core I., Solubility of oxygen in molten iron at high temperatures, Earth Planet. Sci. Lett., 71, 85-93, 1984.

Ohtani, E., A. E. Ringwood, and W. Hibberson, Composition of the core, II, Effect of high pressure on solubility of $\mathrm{FeO}$ in molten iron, Earth Planet. Sci.Lett, 71, 94 $103,1984$.

Rigden, S. M., T. J. Ahrens, and E. M. Stolper, Densities of liquid silicates at high pressures, Science, 226, 1071$1074,1984$.

Ringwood, A. E., The chemical composition and origin of the earth, in Advances in Earth Science, edited by $P$ M. Hurley, pp. 287-356, MIT Press, Cambridge, Mass., 1966

Ringwood, A. E., Origin of the Earth and the Moon, 295 pp., Springer-Verlag, New York, 1979.

Robie, R. A., B. S. Hemingway, and J. R. Fisher, Thermodynamic properties of minerals and related substances at $298.15 \mathrm{~K}$ and 1 Rar $\left(10^{5}\right.$ Pascals) pressure and at higher temperatures, U. S. Geol. Surv. Bull., 1452, 298310,1978

Simakov, G. V., M. N. Pavlovskiy, N. G. Kalashnikov, and R. F. Trunin, Shock compressibility of twelve minerals, Izv. Phys. Solid Earth, 488-492, 1974.

Simmons, G., and F. Birch, Elastic constants of pyrite J. Appl. Phys., 34, 2736-2738, 1963.

Simmons, G., and H. Wang, Single Crrstal Elastic Constants and Calculated Aggregate Properties: A Handbook 2nd ed., 370 pp., MIT Press, Cambridge, Mass., 1971.

Skinner, B. J., Thermal expansion, in Handbook of Physical Constants, Mem. 97, edited by S. P. Clark, Jr. pp. 75-96, Geological Society of America, Boulder, Colo., 1966

Stacey, F. D., Physics of the Earth, 2nd ed., 414 pp., John Wiley, New York, 1977

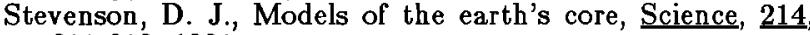
611-619, 1981

Vassiliou, M. S., and T. J. Ahrens, Limited aperture light source streak photography, Rev. Sci. Instrum., 53 (1) 108-109, 1982. 
Vaughan, D. J., and J. R. Craig, Mineral Chemistry of Metal Sulfides, 493 pp., Cambridge University Press, New York, 1978 .

Watt, J. P., G. F. Davies, and R. J. O'Connell, The elastic properties of composite materials, Rev. Geophys. 14, $541-563,1976$.

Williams, Q., R. Jeanloz, J. Bass, B. Svendsen, and T. J. Ahrens, The melting curve of iron to 250 Gigapascals: A constraint on the temperature at Earth's center, Science, 236, 181-182, 1987.
T. J. Ahrens, Seismological Laboratory 252-21, California Institute of Technology, Pasadena, CA 91125.

$R$. Jeanloz, Department of Geology and Geophysics, University of California, Berkeley, CA $\mathbf{9 4 7 2 0 .}$

(Received July 30, 1986;

revised June 5, 1987;

accepted June 9, 1987.) 